\title{
Vertical profiles of aerosol optical properties over central Illinois and comparison with surface and satellite measurements
}

\author{
P. J. Sheridan ${ }^{1}$, E. Andrews ${ }^{1,2}$, J. A. Ogren ${ }^{1}$, J. L. Tackett ${ }^{3}$, and D. M. Winker ${ }^{4}$ \\ ${ }^{1}$ NOAA Earth System Research Laboratory, Boulder, CO, USA \\ ${ }^{2}$ CIRES, University of Colorado, Boulder, CO, USA \\ ${ }^{3}$ Science Systems and Applications, Inc., Hampton, VA, USA \\ ${ }^{4}$ NASA Langley Research Center, Hampton, VA, USA
}

Correspondence to: P. J. Sheridan (patrick.sheridan@ noaa.gov)

Received: 6 June 2012 - Published in Atmos. Chem. Phys. Discuss.: 12 July 2012

Revised: 20 November 2012 - Accepted: 28 November 2012 - Published: 10 December 2012

\begin{abstract}
Between June 2006 and September 2009, an instrumented light aircraft measured over 400 vertical profiles of aerosol and trace gas properties over eastern and central Illinois. The primary objectives of this program were to (1) measure the in situ aerosol properties and determine their vertical and temporal variability and (2) relate these aircraft measurements to concurrent surface and satellite measurements. The primary profile location was within $15 \mathrm{~km}$ of the NOAA/ESRL surface aerosol monitoring station near Bondville, Illinois. Identical instruments at the surface and on the aircraft ensured that the data from both platforms would be directly comparable and permitted a determination of how representative surface aerosol properties were of the lower column. Aircraft profiles were also conducted occasionally at two other nearby locations to increase the frequency of A-Train satellite underflights for the purpose of comparing in situ and satellite-retrieved aerosol data. Measurements of aerosol properties conducted at low relative humidity over the Bondville site compare well with the analogous surface aerosol data and do not indicate any major sampling issues or that the aerosol is radically different at the surface compared with the lowest flyby altitude of $\sim 240 \mathrm{~m}$ above ground level. Statistical analyses of the in situ vertical profile data indicate that aerosol light scattering and absorption (related to aerosol amount) decreases substantially with increasing altitude. Parameters related to the nature of the aerosol (e.g., single-scattering albedo, Ångström exponent, etc.), however, are relatively constant throughout the mixed layer, and do not vary as much as the aerosol amount throughout the profile. While individ-
\end{abstract}

ual profiles often showed more variability, the median in situ single-scattering albedo was $0.93-0.95$ for all sampled altitudes. Several parameters (e.g., submicrometer scattering fraction, hemispheric backscattering fraction, and scattering Ångström exponent) suggest that the fraction of smaller particles in the aerosol is larger near the surface than at high altitudes. The observed dependence of scattering on size, wavelength, angular integration range, and relative humidity, together with the spectral dependence of absorption, show that the aerosol at higher altitudes is larger, less hygroscopic, and more strongly absorbing at shorter wavelengths, suggesting an increased contribution from dust or organic aerosols. The aerosol profiles show significant differences among seasons. The largest amounts of aerosol (as determined by median light extinction profile measurements) throughout most of the sampled column were observed during summer, with the lowest amounts in the winter and intermediate values in the spring and fall. The highest three profile levels (3.1, $3.7,4.6 \mathrm{~km}$ ), however, showed larger median extinction values in the spring, which could reflect long-range transport of dust or smoke aerosols. The aerosols in the mixed layer were darkest (i.e., lowest single-scattering albedo) in the fall, in agreement with surface measurements at Bondville and other continental sites in the US. In situ profiles of aerosol radiative forcing efficiency showed little seasonal or vertical variability. Underflights of the CALIPSO satellite show reasonable agreement in a majority of retrieved profiles between aircraft-measured extinction at $532 \mathrm{~nm}$ (adjusted to ambient relative humidity) and CALIPSO-retrieved extinction, and suggest that routine aircraft profiling programs can 
be used to better understand and validate satellite retrieval algorithms. CALIPSO tended to overestimate the aerosol extinction at this location in some boundary layer flight segments when scattered or broken clouds were present, which could be related to problems with CALIPSO cloud screening methods. The in situ aircraft-collected aerosol data suggest extinction thresholds for the likelihood of aerosol layers being detected by the CALIOP lidar. In this study, aerosol layers with light extinction $(532 \mathrm{~nm})$ values $>50 \mathrm{Mm}^{-1}$ were detected by CALIPSO $\sim 95 \%$ of the time, while aerosol layers with extinction values lower than $10 \mathrm{Mm}^{-1}$ had a detection efficiency of $<2 \%$. For all collocated comparison cases, a $50 \%$ probability of detection falls at an in situ extinction level of $20-25 \mathrm{Mm}^{-1}$. These statistical data offer guidance as to the likelihood of CALIPSO's ability to retrieve aerosol extinction at various locations around the globe.

\section{Introduction}

Unlike the major long-lived trace gases, aerosols are not distributed uniformly in the atmosphere. Locations downwind of major particle sources such as deserts, biomass burning regions and large cities often have heavy atmospheric aerosol burdens while areas remote from major sources have relatively low aerosol loadings. The composition and size distribution of these atmospheric particles, and thus their optical and hygroscopic properties, also vary widely from place to place and over time. These aerosol properties depend not only on the source emissions but also the subsequent atmospheric processing including condensation, coagulation and removal, which can be quite different for different aerosol types. This inhomogeneity in aerosol amount and character coupled with the relative paucity of sustained observations around the globe makes it difficult to estimate the direct aerosol radiative forcing effect on global climate (e.g., Charlson et al., 1991; Yu et al., 2006).

In order to better understand aerosol radiative forcing and the effects of aerosols on the global and regional climate, long-term measurements of aerosol optical properties are being made by the National Oceanic and Atmospheric Administration (NOAA) Earth System Research Laboratory (ESRL) (e.g., Bodhaine, 1983, 1995; Bodhaine and Dutton, 1993; Delene and Ogren, 2002) and other organizations (e.g., the Global Atmosphere Watch network coordinated by the World Meteorological Organization) at locations around the world. Many major surface regions remain undersampled, however, and very few long-term measurement efforts have been made above the surface. Despite these dedicated aerosol monitoring programs providing important model initialization and validation data, the largest uncertainties in modeling climate change remain those associated with aerosols (e.g., IPCC, 2007; Myhre, 2009). Part of the problem is that it is unknown to what extent the surface measurements at many locations represent the aerosols above them in the troposphere. For reliable aerosol radiative forcing estimates to be made, knowledge of the aerosol optical properties, at least up to the top of the mixed layer where most of the aerosols reside, is necessary.

Remote sensing methods, including aerosol optical depth retrievals and lidar measurements from both satellite- and surface-based platforms, are clearly useful in helping to understand the vertical distributions of aerosols. These methods have their limitations however. While polar-orbiting satellites provide broad spatial coverage, their sensors require careful validation before meaningful information on the nature of the aerosols can be extracted from the retrievals. It has also recently been shown that errors in the assumed aerosol profiles can cause significant errors in the aerosol optical thickness retrieved from satellites (Rozwadowska, 2007). Inversion algorithms utilizing remote sensing measurements from ground-based sun-sky radiometers (e.g., multi-wavelength Cimel sun photometers) are promising (Holben et al., 1998, 2001; Eck et al., 2003, 2005), but spatial coverage is quite limited compared to satellite measurements. Additionally, the aerosol properties obtained from sun photometer measurements are representative of the entire column rather than those at any specific altitude, have difficulties with the retrievals of intensive properties for lower aerosol loadings, and are normally limited to measure in clear sky conditions (e.g., Dubovik and King, 2000).

Lidar routinely provides profiles of aerosol extinction and backscattering ("extensive" aerosol properties, related to the amount of aerosol present, Ogren, 1995). At this time, however, lidar retrievals of the aerosol intensive properties (related to the nature of the aerosols rather than the amount, Ogren, 1995) necessary to determine radiative forcing remain less certain (Müller et al., 2001; Veselovskii et al., 2005). A large data set has in the last few years been collected by NASA using their High Spectral Resolution Lidar (HSRL) instrument and has shown promise in measuring some intensive aerosol properties including lidar ratio, depolarization, and backscatter wavelength dependence (Rogers et al., 2009).

Instrumented aircraft are capable of making many of the in situ aerosol measurements necessary for validating the remote sensing methods. In addition, they provide valuable data for initialization and testing of global aerosol transport models and for relating surface measurements to those in the overlying column. Most of the historical airborne measurements have been during short "deployment-based" studies (e.g., Verver et al., 2000; Ramanathan et al., 2001; Ferrare et al., 2006; Shinozuka et al., 2007) intensely studying the atmosphere for relatively brief periods of time (e.g., several weeks). The duration of these projects typically limits their usefulness in comparing the airborne data with surface or remote sensing climatologies and is insufficient to determine seasonal aerosol variability or long-term trends to assess climatic effects. Unfortunately, not many aircraft 
programs have been conducted even intermittently in one region over multiple years (e.g., Taubman et al., 2006; Hains et al., 2008), and even fewer can be considered true long-term monitoring programs (e.g., Andrews et al., 2004, 2011).

In an effort to characterize when, how often, and under what conditions surface aerosol measurements are representative of the lower atmospheric column, ESRL recently conducted long-term aircraft measurement programs over two heavily-instrumented surface aerosol monitoring stations. These sites were the Department of Energy/Atmospheric Radiation Measurement (DOE/ARM) program Southern Great Plains (SGP) Central Facility near Lamont, Oklahoma, and the NOAA surface aerosol monitoring station (BND) near Bondville, Illinois. The primary objectives of these programs were to obtain statistically robust data sets of the vertical distribution of aerosol properties for use by modelers in the evaluation of aerosol radiative forcing and to relate these properties to those measured by similar or identical instruments at the surface. To accomplish these primary goals, dedicated aerosol systems were built into small Cessna aircraft and were designed using identical inlets and many of the same instruments, so that measurements would be directly comparable between the two aircraft systems and between surface and airborne stations. The Oklahoma aircraft flew 597 complete research profiles between March 2000 and December 2007, and results have been reported in Andrews et al. (2004) and Andrews et al. (2011). The Illinois aircraft is the NOAA/ESRL Airborne Aerosol Observatory (AAO), and it flew 2-3 times per week between June 2006 and September 2009 for a total of 401 research profiles.

The measurements taken aboard the two aircraft were used to answer the following scientific questions:

- How do aerosol properties in the atmosphere over a rural region vary over different time scales (e.g., monthly or seasonally)?

- How do aerosol properties change with altitude in the lower atmospheric column?

- At what times, and under what conditions can surfacebased measurements of these properties be used to calculate the direct aerosol radiative forcing from a measured aerosol optical depth?

A secondary objective of the AAO project was to contribute to the verification of aerosol remote sensing retrieval algorithms used by several satellites, including the "A-Train" AQUA and CALIPSO satellites and the TERRA satellite. This was accomplished by coordination of aircraft activities with satellite overflights and generation of value-added products for comparison with the lidar and column-average sunphotometer data. The satellite measurements require "air truth" in situ measurements to identify and constrain systematic errors in the retrievals of aerosol physical properties. Improvements in these algorithms will improve the quality of height dependent information from CALIPSO and other backscatter lidars.

This paper presents the statistics of the $>3$-yr AAO record of in situ aerosol optical property measurements. The vertical profiles of aerosol properties over the BND site are useful in determining the statistical variability of aerosol properties with time and altitude in central Illinois. While the AAO data are not of sufficient duration to determine long-term aerosol trends, they are useful in assessing seasonal variability and also in relating the atmospheric and surface aerosol measurements. Measurements of in situ AAO light extinction are compared with CALIPSO satellite lidar (CALIOP) extinction data, and the results suggest a cost-effective way to verify satellite-borne lidar retrievals. Comparisons of AAO light extinction with aerosol optical thickness measurements from the Bondville AERONET sun photometer are reported in another paper (Esteve et al., 2012).

\section{Methods}

The in situ aerosol data were obtained by flying an instrumented light aircraft (Cessna T206H) near NOAA's regional aerosol monitoring station near Bondville, Illinois, $\left(40.053^{\circ} \mathrm{N}, 88.372^{\circ} \mathrm{W}, 220 \mathrm{~m}\right.$ above mean sea level - a.s.l.). This site is an anthropogenically perturbed, continental station located at the Illinois State Water Survey's Bondville Environmental and Atmospheric Research Site (BEARS). It is located $6.5 \mathrm{~km}$ south of Bondville (population $\sim 450$ ), $16 \mathrm{~km}$ southwest of Champaign-Urbana (population $~ 230000$ ), and is surrounded by corn and soybean fields. The prevailing wind directions over an entire year at the site cover a range from $\mathrm{S}$ to $\mathrm{WNW}$ (i.e., predominantly upwind of Champaign-Urbana). Climatologies of surface aerosol optical properties observed at the Bondville site have been reported by Koloutsou-Vakakis et al. (2001) and Delene and Ogren (2002).

A schematic of instrument rack locations in the Cessna aircraft is shown in Fig. 1. The locations of instruments are reported in Table 1, which also lists details about the measurements and the species or parameter measured. The main aerosol sample line running to the optics rack $(\mathrm{O})$ and the $\mathrm{ABC}$ rack system is shown as a red line.

The aerosol sample inlet was made of anodized aircraftgrade $\mathrm{Al}$ alloy, based on the shrouded inlet design of the University of Hawaii (Clarke et al., 2004; McNaughton et al., 2007). The inlet was positioned on the starboard wing about $2 \mathrm{~m}$ from the fuselage, well outside of the propeller wash. The exit plane of the inlet was modified for a smooth transition to $22.2 \mathrm{~mm}$ internal diameter (ID) stainless steel tubing, and this inlet line entered the leading edge of the wing. The front of the aerosol inlet extended $\sim 50 \mathrm{~cm}$ forward of the leading edge of the wing, sufficient to get into the free air stream at $\sim 50 \mathrm{~m} \mathrm{~s}^{-1}$ airspeed with little disturbance from the forward projection of the wing wake based on tufting studies 
Table 1. Major instruments and primary measurements on the AAO aircraft.

\begin{tabular}{lllc}
\hline Aircraft Location & Instruments & Measurements/Species & Wavelengths (nm) \\
\hline Rack O & $3-\lambda$ Nephelometer & $\sigma_{\mathrm{sp}}$ and $\sigma_{\mathrm{bsp}}($ no size cut, low RH) & $450,550,700$ \\
& Three 1- $\lambda$ Nephelometers & $\sigma_{\mathrm{sp}}\left(D_{\mathrm{p}}<1 \mu \mathrm{m}, 3\right.$ different RHs $)$ & 545 \\
Rack A & CPC & Total particle number $\left(D_{\mathrm{p}}>10 \mathrm{~nm}\right)$ & - \\
& SEMS & Particle size distribution $\left(22 \mathrm{~nm}<D_{\mathrm{p}}<480 \mathrm{~nm}\right)$ & - \\
Rack B & PILS & Soluble fraction major ions & - \\
Rack C & PSAP & $\sigma_{\text {ap }}$ (no size cut $)$ & $467,530,660$ \\
& Ozone monitor & Ozone mixing ratio & - \\
Rack F & Gas flask sampler & Trace gases & - \\
\hline
\end{tabular}

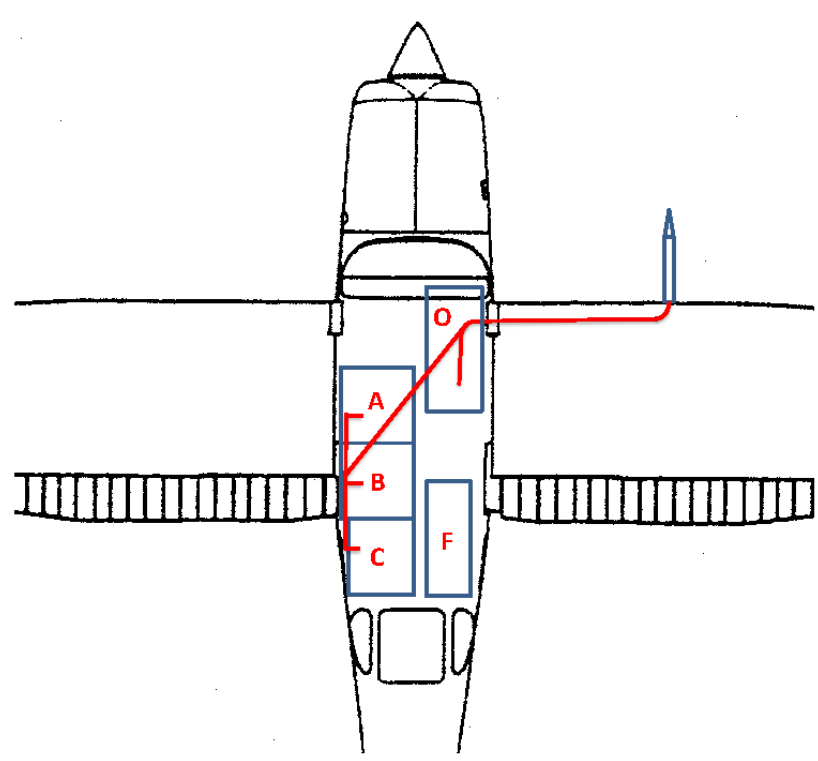

Fig. 1. Schematic of the AAO Cessna T206H aircraft showing aerosol inlet and instrument racks. Main aerosol sample line is shown in red. Lettered areas are described in the text and in Table 1.

done at that location. Those same tufting studies guided our angling of the inlet downward by several degrees relative to the angle of the wing to match the orientation of the streamlines in level flight when the aircraft was burdened with a low-to-medium load of fuel. Adjustment of the inlet orientation during flight was not possible, so non-axial sampling by up to a few degrees is possible early in the flight. Sampling later in the profiles, especially that conducted down in the boundary layer where most of the aerosol resides, was expected to be close to isoaxial.

The aerosol sample flow rate was maintained at $\sim 60 \mathrm{lpm}$ so that the inlet would sample isokinetically at the nominal $50 \mathrm{~m} \mathrm{~s}^{-1}$ research speed of the Cessna. Upon entering the wing the inlet tubing made a $90^{\circ}$ gentle bend $(7.6-\mathrm{cm}$ radius of curvature) toward the fuselage followed by an approximately level run to the cabin. Inside the cabin, the sample flow encountered a flow splitter that directed a portion of the flow $(16.7 \mathrm{lpm})$ downward into the optics rack. The flow rate was controlled by a volume flow controller (Brechtel Manufacturing Inc.), and this flow control was necessary due to a downstream aerosol cyclone. The remainder of the aerosol flow was passed across the cabin ceiling to the $A B C$ rack system.

The performance of the University of Hawaii (UH) inlet has been described in detail (Huebert et al., 2004; McNaughton et al., 2007). The results indicate a $50 \%$ passing efficiency for $\sim 5 \mu \mathrm{m}$ aerodynamic diameter particles for the UH inlet, including its short length of inlet tubing, at an airspeed of $120 \mathrm{~m} \mathrm{~s}^{-1}$. Scaling this result to our lower airspeed suggests a $50 \%$ passing efficiency through this shrouded diffuser inlet for particles of 6-7 $\mu \mathrm{m}$ aerodynamic diameter. The particle passing efficiency of the AAO sample line tubing downstream of the inlet was not determined experimentally, but was calculated using the widely available aerosol calculator spreadsheet from Paul Baron (e.g., http://aerosols.wustl. edu/AAARworkshop08/html/calculator.htm). For this exercise, we neglected electrostatic (all tubing was conductive) and thermophoretic losses, and calculated the combined effect of gravitational, inertial, and diffusional losses in the turbulent flow conditions inside the AAO inlet tubing for particles of different aerodynamic diameters. Figure 2 indicates that the inlet plumbing to the inlet of the reference nephelometer in the optics rack efficiently passed particles over the range of $\sim 20 \mathrm{~nm}$ up to $\sim 5 \mu \mathrm{m}$. The particle transmission efficiency to the flow splitter in the ABC rack system experienced only slightly higher transmission losses at the low and high ends of the particle size distribution due to the longer run of tubing. The combination of literature results and loss calculations indicates that the AAO inlet system (including the diffuser inlet plus sample line tubing) efficiently passes particles up to about $5 \mu \mathrm{m}$ aerodynamic diameter.

The optics rack was positioned where the co-pilot's seat would normally be and housed a three-wavelength $(3-\lambda)$ integrating nephelometer (TSI Model 3563) for measurement of the total light scattering coefficients $\left(\sigma_{\mathrm{sp}}\right)$ and hemispheric backscattering coefficients $\left(\sigma_{\mathrm{bsp}}\right)$. Measurement details and uncertainties for the TSI nephelometer have been described elsewhere (Anderson et al., 1999; Sheridan et al., 2002). 


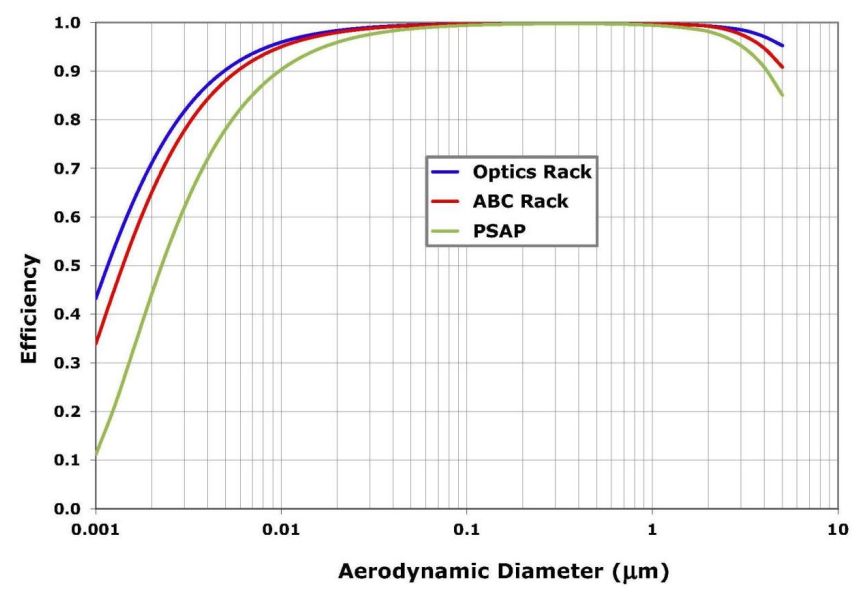

Fig. 2. Particle transmission efficiency through the aerosol sample lines between the main inlet and the Optics and ABC racks (calculated using Paul A. Baron's aerosol calculator spreadsheet, AEROCALC.XLS). Curves represent the combined effects of gravitational, inertial and diffusional losses in a turbulent flow environment.

Ambient aerosol properties for this program (e.g., singlescattering albedo $\left(\omega_{0}\right)>0.7$ and minor coarse mode fractions, as discussed by Massoli et al., 2009) were such that the routine nephelometer correction (i.e., truncation) methods described in Anderson and Ogren (1998) were appropriate and, thus, were applied in this study.

Sample aerosols entering the optics rack passed through the $3-\lambda$ nephelometer (controlled at a relative humidity (RH) $\leq 40 \%$ by a small heater) and then entered a sharp cut cyclone (BGI Inc. model SCC 2.229-PM1), which produced a 1- $\mathrm{mm}$ aerodynamic diameter size cut aerosol at a volume flow rate of $16.7 \mathrm{lpm}$. This aerosol was then fed in parallel into three single-wavelength $(1-\lambda)$ integrating nephelometers (Radiance Research Model M903), each operating at a volume flow rate of $\sim 5.6 \mathrm{lpm}$, for measurement of the submicrometer $\sigma_{\mathrm{sp}}$. The 1- $\lambda$ nephelometer data were also corrected for truncation using the correction factors presented in Anderson and Ogren (1998). The question of whether the Anderson and Ogren (1998) corrections, which were published to correct TSI nephelometer truncation errors, can also be used for the Radiance Research nephelometers has been answered in the recent study of Müller et al. (2009). This study shows that the measured illumination functions for the Radiance Research and TSI nephelometers are very similar, and these coupled with the internal instrument geometries provide truncation correction factors for the Radiance Research nephelometer that agree quite closely (within a few percent up to $1-\mu \mathrm{m}$ aerodynamic diameter) with the original Anderson and Ogren (1998) corrections. The three $1-\lambda$ nephelometers were each held at a different stable RH through the use of small proportional-integral-derivative (PID) controllers (low: $\leq 40 \% \mathrm{RH}$, med: $65 \% \mathrm{RH}$, high: $85 \% \mathrm{RH}$ ) for determination of the submicrometer aerosol hygroscopic growth factor.
The remainder of the $60 \mathrm{lpm}$ inlet flow was passed across the cabin to the $\mathrm{ABC}$ rack system. Rack A housed a condensation particle counter (CPC, TSI Model 3010) for measuring condensation nucleus $(\mathrm{CN})$ concentration and a scanning electrical mobility sizer (Brechtel Manufacturing Inc. Model SEMS) for measuring aerosol size distributions for particles between 22 and $480 \mathrm{~nm}$. Rack B contained a ParticleInto-Liquid Sampler (PILS, Brechtel Manufacturing Inc.) for post-flight determination of aerosol ionic composition. Aerosol samples of $\sim 3$ min duration were collected by injection into small sealed vials at $5 \mathrm{~min}$ intervals and subsequently sent to NOAA's Pacific Marine Environmental Laboratory for major ion analysis. Rack $\mathrm{C}$ housed a $3-\lambda$ filter-based light absorption instrument (Radiance Research Model PSAP) for measurement of the aerosol light absorption coefficient $\left(\sigma_{\mathrm{ap}}\right)$ and a continuous ozone monitor (2B Technologies Model 205). Rack F was a removable suitcase sampler (http://www.esrl.noaa.gov/gmd/ccgg/aircraft/index. html) that contained 12 glass flasks for trace gas collection and post-flight analysis at NOAA/ESRL (e.g., $\mathrm{CO}_{2}, \mathrm{CO}$, $\mathrm{CH}_{4}, \mathrm{~N}_{2} \mathrm{O}, \mathrm{H}_{2}, \mathrm{SF}_{6}$, isotopes of $\mathrm{CO}_{2}$ and $\mathrm{CH}_{4}$, multiple haloand hydrocarbons). A gas sample was collected near the midpoint of each of the 10 level segments of each research profile. Typically, a second flask would be collected on one of the higher altitude runs to assess analytical precision and also on the lowest leg near the BND site on the way back to the airport. The gas inlets for the ozone monitor and the suitcase sampler were rear-facing inlets located on a modified window plate below the port wing.

PSAP measurements were corrected for sample area, flow rate and nonidealities in the manufacturer's calibration (Bond et al., 1999; Ogren, 2010). Measurement uncertainties for the PSAP have been described in detail elsewhere (Anderson et al., 1999; Bond et al., 1999; Sheridan et al., 2002). The AAO PSAP was modified to accommodate a small $(\sim 5 \mathrm{~W})$ heater on its internal inlet line just upstream of the optical block. The heating was gentle, typically only a few degrees, but the metal block was kept warm relative to the sample so the $\mathrm{RH}$ remained low. Our own tests suggest that the heater kept the $\mathrm{RH}$ at the filter below $40 \%$ most of the time and an $\mathrm{RH}$ of $50 \%$ at the filter would have been exceeded only during sampling of very humid air, which was not common in this program. The heater was not actively controlled to maintain a specific low $\mathrm{RH}$, but $\mathrm{RH}$ variability at low $\mathrm{RH}$ is not believed to influence the measurements as strongly as RH variability at high RH. Figure 2 shows the calculated particle transmission efficiency through the entire sample line to the PSAP inlet. This calculation shows higher particle losses at the ends of the size distribution for the PSAP relative to the $A B C$ rack system due to an added length of smaller diameter ( $\sim 6 \mathrm{~mm} \mathrm{ID)}$ conductive tubing between the $\mathrm{ABC}$ splitter and the PSAP inlet. The PSAP inlet line particle passing efficiency compares favorably, however, to the transmission efficiency of the inlet tubing to the optics rack over the optically-important $20 \mathrm{~nm}$ to $2 \mu \mathrm{m}$ size range. At 
aerodynamic diameters of $20 \mathrm{~nm}$ and $2 \mu \mathrm{m},>95 \%$ of all sampled particles reached the AAO instruments. This is important for the determination of the single-scattering albedo, $\omega_{0}$, which has both a scattering and an absorption component. Inlet losses should be similar to those experienced by the nephelometer for valid comparisons between scattering and absorption.

Unfortunately the SEMS and PILS measurements were quite intermittent in nature due to numerous problems associated with operating in an aircraft environment. Vibration appears to have been one of the major issues, causing internal circuit boards and/or connectors in the SEMS to come loose during flights and the injection needle for the PILS to frequently stick in the retracted position. Because we have such a limited subset of the SEMS and PILS data available, only aerosol optical properties and particle number concentrations are included in the long term statistics presented in this paper.

The basic AAO aerosol optical measurements were used to derive a number of other key aerosol properties that are used in radiative transfer models and for the determination of direct aerosol radiative forcing (Haywood and Shine, 1995). These calculated properties and equations are listed in Table 2. The aerosol light extinction coefficient, $\sigma_{\mathrm{ep}}$, is the sum of the scattering and absorption coefficients at any given wavelength. The scattering and absorption Ångström exponents (Ensor et al., 1972; Bodhaine, 1983; Moosmüller et al, 2009), $\stackrel{\circ}{s}_{s}$ and $a_{a}$, respectively, describe the wavelengthdependence of light scattering and absorption based on a power law relationship. For comparison with historical data, we used a common two-point power-law expression for cal-

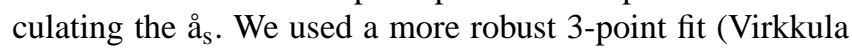
et al., 2011) for the $a_{a}$ determination. The submicrometer scattering ratio, $R_{\mathrm{sp}}$, is the fraction of light scattering at a given wavelength due to aerosol particles smaller than $1 \mu \mathrm{m}$ aerodynamic diameter. As discussed above the inlet and inlet tubing efficiently pass particles up to $\sim 5 \mu \mathrm{m}$ aerodynamic diameter, so the "total" size fraction for AAO measurements includes particles up to $\sim 5 \mu \mathrm{m}$. The $\omega_{0}$ is the fraction of light extinction due to scattering.

A number of other parameters describe the angular scattering properties of the aerosol. The $\sigma_{\mathrm{bsp}}$ and $\sigma_{\mathrm{sp}}$ measurements are used to calculate the fraction of light scattered in the backward hemisphere (the hemispheric backscatter fraction, $b$ ) at each wavelength. The hemispheric backscatter fraction is related to the aerosol asymmetry parameter, $g$, which describes the angular scattering phase function, and is estimated from the empirical relationship presented in Andrews et al. (2006). The upscattered fraction $\beta$, or the fraction of incoming light scattered backward to space by atmospheric aerosols, has been related to $b$ by Wiscombe and Grams (1976), and a second-order curve fit of the points in their Fig. 3 as reported in Sheridan and Ogren (1999) provides the parameterization shown in Table 2.

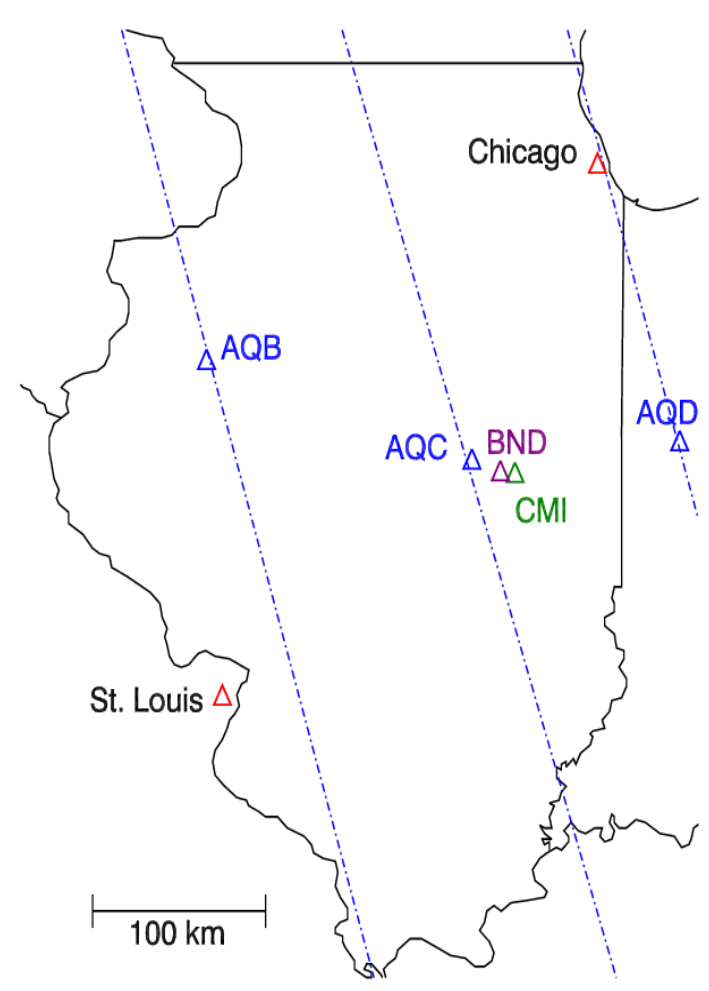

Fig. 3. Map of the study area showing the three AAO profile locations, the approximate A-Train satellite tracks, the BND surface monitoring site, and the AAO base of operations (CMI airport).

The submicrometer aerosol scattering hygroscopic growth factor, $f(\mathrm{RH})$, for each altitude was estimated using a subset of measurements from the three $1-\lambda(545 \mathrm{~nm})$ nephelometers. These nephelometers measured submicrometer scattering coefficients at three fixed RH's $(\leq 40 \%, \sim 65 \%$, and $\sim 85 \%$ ), and the mean scattering growth function for each flight segment was determined by a power-law fit of the three sets of measurements. The $f(\mathrm{RH})$ equation in Table 2 shows how the fit parameter $\gamma$ is used to derive $f(\mathrm{RH})$, which by definition in this work is the relationship between $\sigma_{\mathrm{sp}, \mathrm{RH}=85 \%}$ relative to $\sigma_{\mathrm{sp}, \mathrm{RH}=40 \%}$. In this equation $\mathrm{RH}_{\mathrm{wet}}=$ 85 and $\mathrm{RH}_{\mathrm{dry}}=40$. The $\gamma$ parameter describes the curvature of the RH-dependence of scattering (Kasten, 1969) and has been used to characterize aerosol hygroscopicity in other studies (e.g., Gassó et al., 2000; Sheridan et al., 2002; Andrews et al., 2004; Hains et al., 2008). The same equation is used to adjust the submicrometer aerosol scattering values measured on each flight segment in the low-RH, 1- $\lambda$ nephelometer to ambient RH conditions. For this adjustment, the median $\gamma$ value for each flight level acquired for the subset of flight segments with valid hygroscopic growth measurements (i.e., all three nephelometers functioning properly) was used with $\mathrm{RH}_{\text {dry }}$ now being the $\mathrm{RH}$ measured in the low- $\mathrm{RH}$ nephelometer, $\mathrm{RH}_{\text {wet }}$ being the ambient $\mathrm{RH}, \sigma_{\mathrm{sp}, 40 \%}$ being replaced by the $\sigma_{\mathrm{sp} \text {,dry }}$ (i.e., $\sigma_{\mathrm{sp}}$ measured in the low$\mathrm{RH}$ nephelometer) and solving for the $\sigma_{\mathrm{sp} \text {, wet }}$ (ambient $\sigma_{\mathrm{sp}}$ ). 
Table 2. Parameters and equations used for calculation of aerosol optical properties.

\begin{tabular}{|c|c|}
\hline Parameter & Equation \\
\hline Extinction coefficient & $\sigma_{\mathrm{ep}}=\sigma_{\mathrm{sp}}+\sigma_{\mathrm{ap}}$ \\
\hline Scattering Ångström exponent & $\stackrel{\circ}{\mathrm{s}}=-\log \left(\sigma_{\mathrm{sp}, \lambda 1} / \sigma_{\mathrm{sp}, \lambda 2}\right) / \log (\lambda 1 / \lambda 2)$ \\
\hline Absorption Ångström exponent & $\stackrel{\circ}{\mathrm{a}}=-\log \left(\sigma_{\mathrm{ap}, \lambda(i)} / \log (\lambda(i))\right.$ \\
\hline Submicron scattering ratio & $R_{\mathrm{sp}}=\sigma_{\mathrm{sp}, D_{\mathrm{p}}}<1 \mu \mathrm{m} / \sigma_{\mathrm{sp}, \text { total }}$ \\
\hline Hemispheric backscatter fraction & $b=\sigma_{\mathrm{bsp}} / \sigma_{\mathrm{sp}}$ \\
\hline Asymmetry parameter & $g=-7.1439 b^{3}+7.4644 b^{2}-3.9636 b+0.9893$ \\
\hline Upscattered fraction & $\beta=0.0817+1.8495 b-2.9682 b^{2}$ \\
\hline Single-scattering albedo & $\omega_{0}=\sigma_{\mathrm{sp}} / \sigma_{\mathrm{ep}}=\sigma_{\mathrm{sp}} /\left(\sigma_{\mathrm{sp}}+\sigma_{\mathrm{ap}}\right)$ \\
\hline Hygroscopic growth factor & $f(\mathrm{RH})=\sigma_{\mathrm{sp}, 85 \%} / \sigma_{\mathrm{sp}, 40 \%}=\left(\left(1-\left(\mathrm{RH}_{\mathrm{wet}} / 100\right)\right) /\left(1-\left(\mathrm{RH}_{\mathrm{dry}} / 100\right)\right)\right)^{-\gamma}$ \\
\hline
\end{tabular}

Table 3. AAO profile locations and details.

\begin{tabular}{llcc}
\hline Profile ID & Profile Type & Location (Lat., Lon.) & Number of Profiles \\
\hline LODG & Routine profile at Lodge location & $40.117^{\circ} \mathrm{N}, 88.567^{\circ} \mathrm{W}$ & 297 \\
TERA & TERRA satellite underflight at Lodge location & $40.117^{\circ} \mathrm{N}, 88.567^{\circ} \mathrm{W}$ & 41 \\
AQB1 & A-Train satellite underflight on B Track & $40.717^{\circ} \mathrm{N}, 90.408^{\circ} \mathrm{W}$ & 20 \\
AQC1 & A-Train satellite underflight at Lodge location (C Track) & $40.117^{\circ} \mathrm{N}, 88.567^{\circ} \mathrm{W}$ & 27 \\
AQD1 & A-Train satellite underflight on D Track & $40.230^{\circ} \mathrm{N}, 87.128^{\circ} \mathrm{W}$ & 16 \\
\hline
\end{tabular}

The effect of using the median altitude-specific $\gamma$ value as opposed to a $\gamma$ value determined for each flight segment is discussed in Sect. 3.2.

The basic sampling strategy employed for the AAO project was to use a dedicated light aircraft to sample atmospheric aerosols at predetermined altitudes above an instrumented ground station that makes similar or identical measurements and/or below a satellite making aerosol measurements. Table 3 provides the locations of the AAO profiles and the number of profiles flown at each location, while Fig. 3 shows a map of the area with profile locations and A-Train satellite tracks indicated.

To be able to make valid comparisons with the remote column sensors, the AAO aircraft had to reach altitudes above the vast majority of the aerosols, and unbroken clouds could not be present. We have no long-term lidar data from this region to assess aerosol extinction vs. altitude; however, several studies suggest that large extinction at high altitudes is rare over the US. Yu et al. (2010) reports a summary of CALIPSO data over the eastern US and shows that negligible extinction was observed at altitudes of $4.6-10 \mathrm{~km}$ in 2007. Likewise, Vernier et al. (2011) demonstrate that the zonally-averaged aerosol optical depth (AOD) of stratospheric aerosols at $20-30 \mathrm{~km}$ altitude at $20-50^{\circ} \mathrm{N}$ latitude during the study period was $<0.005$. Finally, a detailed Raman lidar study was done at another instrumented midlatitude continental site (the DOE/ARM SGP site, Turner et al., 2001) where the AAO sister aircraft operated for many years. These lidar data represent a wide variety of atmospheric conditions and analyses were analyzed based on time of day, season, and integrated amount. The results indicate that for AOD $\leq 0.4$, our highest flight altitude ( $\sim 4.6 \mathrm{~km}$ a.s.l.) would be above $>95 \%$ of column aerosol extinction. Based on analysis of our AAO profile data, significant aerosol loadings at the highest levels of our profiles were rarely observed, so the SGP lidar study results may be representative of other mid-continental sites like BND. Interestingly, the lidar observed some elevated aerosol layers during high AOD (0.6-1.5) cases; these layers were at and above the highest flight altitudes and occurred most frequently in the springtime at the SGP site. This observation is consistent with our springtime in situ aerosol profiles over central Illinois, which are reported below.

Our strategy for operating when clouds were present was for the AAO pilot to assess the current extent of cloudiness in the region and the cloud forecast prior to takeoff. For routine profiles conducted near the small town of Lodge (with no satellite overflight), one of two conditions needed to be met; either cloud coverage was broken (clouds covering 6/10 to $9 / 10$ of the sky) or less with a forecast for no increase in cloudiness, or there was a shallow solid layer of (nonprecipitating) cloud that spanned no more than three adjacent flight levels (in which case those levels were not sampled). For this reason, some AAO profiles are missing 1-3 level segments. For satellite overflight profiles, cloud fraction must have been no more than scattered (1/10 to 5/10 sky coverage) without a deteriorating forecast. Unfortunately, the forecast was not always correct and there were flights with 


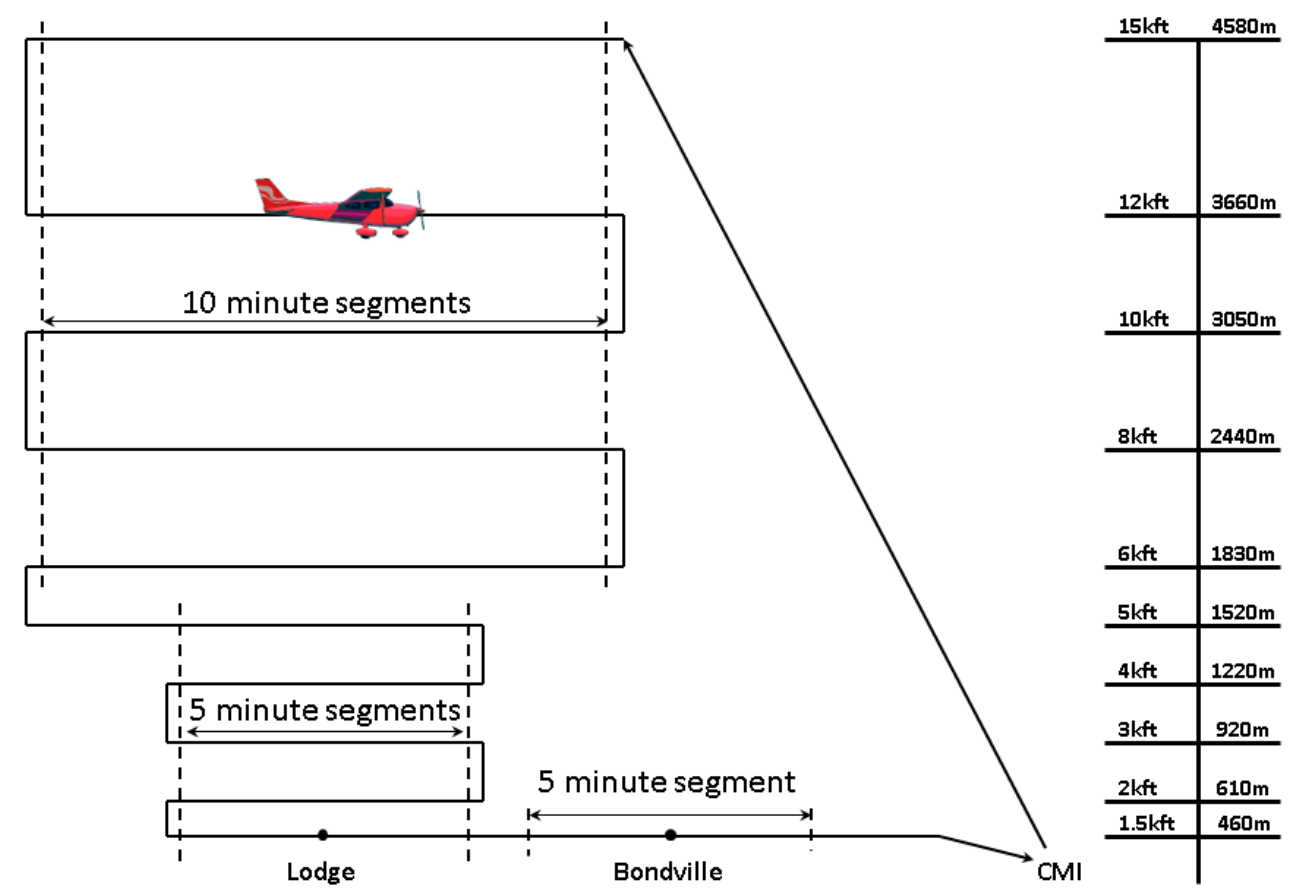

Fig. 4. A typical aircraft vertical profile over the Lodge profile site. Altitudes are relative to mean sea level. A 5-min low pass was typically conducted over the Bondville surface monitoring station on the way back to the airport.

more cloudiness than anticipated, which negatively affected the satellite data retrievals and their comparisons with the aircraft data. In general, we chose to fly on sunny to partly cloudy days; thus our results may be biased toward lower ambient RH conditions.

A diagram depicting a typical research profile over the Lodge sampling location is shown in Fig. 4. For all AAO profiles, level flight segments centered on the profile location were conducted at 4580, 3660, 3050, 2440, 1830, 1520, $1220,920,610$ and $460 \mathrm{~m}$ a.s.l. (corresponding to 15000 , $12000,10000,8000,6000,5000,4000,3000,2000$ and 1500 feet a.s.l.). The altitudes flown were pressure altitudes based on the aircraft altimeter, which in the US are denoted in feet rather than meters. The upper five segments (down to and including the $1830 \mathrm{~m}$ level) were $10 \mathrm{~min}$ in duration to give better averaging statistics and reduced uncertainties in the lower aerosol-loading portion of the profiles. The lower five segments were $5 \mathrm{~min}$ in duration. The Lodge site was chosen as our primary profile location, rather than directly over the BND station, due to FAA concerns over the proximity to the flight approach path for the Champaign-Urbana Willard (CMI) airport. The profile location near Lodge is about $15 \mathrm{~km}$ west-northwest of BND. On these Lodge profiles (labeled LODG, AQC1, and TERA in Table 3), a lowaltitude ( $\sim 460 \mathrm{~m}$ a.s.l, $\sim 240 \mathrm{~m}$ above ground level - a.g.l.) flyby of the BND site was conducted on the way back to the airport to relate the aerosol measurements in the vertical profile to those at the surface site. Therefore, all profiles con- ducted at the Lodge site have two low-altitude segments; one at the bottom of the Lodge profile and one centered $\sim 15 \mathrm{~km}$ away directly over the BND site.

The aerosol system was designed for semi-automated operation such that the pilot had only to turn it on for a pre-flight warm-up, install gas flasks and expendable supplies such as filters and fluids, go through a system checklist to ensure that instruments were working properly, and then proceed to takeoff. Once airborne, the only interaction of the pilot with the research equipment was to press a button near the middle of each level-flight segment to initiate collection of a gas flask sample. On each flight a nephelometer filtered-air check to determine nephelometer background values was automatically performed just after takeoff and on the way back to the airport after completing the profile. Sampling times were limited to daylight hours, but otherwise were quite variable, so that cumulative data represent all daylight hours, days of the week, and seasons of the year. During satellite underflights, takeoff was scheduled such that the airplane was sampling in the boundary layer when the satellite passed over.

\section{Results}

Figure 5 is a histogram showing the number of each type of vertical profile per quarter-year. The AAO program averaged about 30 research profiles per quarter or about one profile every 3 days. An exception was the first quarter of 2008, where an engine problem kept the aircraft grounded 


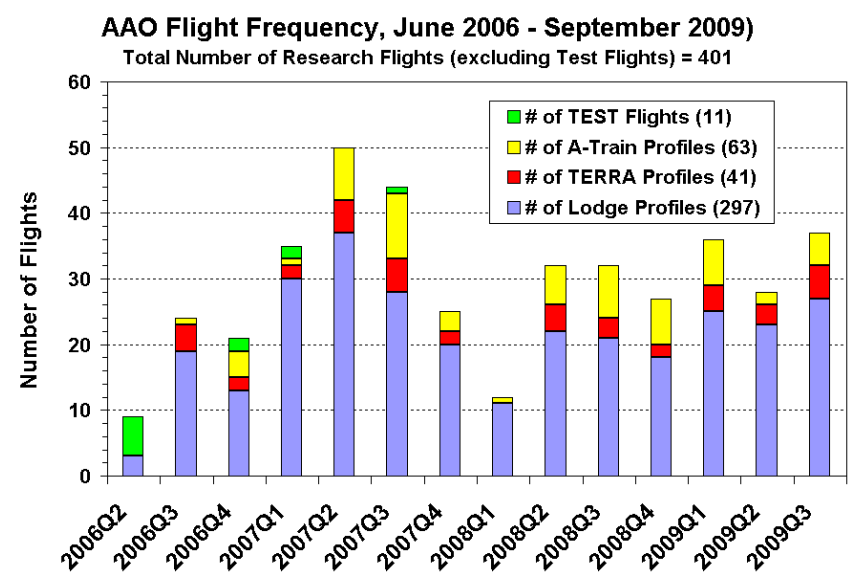

Fig. 5. AAO flight frequency distribution by quarter-year. The routine Lodge and TERRA satellite profiles were all conducted over the Lodge profile location. Each A-Train satellite profile was conducted at one of the three AAO profile locations listed in Table 3.

for nearly 2 months. Profiles conducted during overpasses of the A-Train constellation and TERRA satellites are shown in yellow and red, respectively. About $26 \%$ of the research profiles occurred during satellite overpasses, and this fraction of satellite flights was determined by weather and the more stringent cloud fraction requirement, along with pilot availability and the satellite overpass schedule.

One of the objectives of the AAO program was to determine statistically how representative the surface measurements at the BND site were of those in the lower column. In Fig. 6, the low-altitude flight segments conducted during flybys of the BND site at $\sim 240 \mathrm{~m}$ a.g.l. are compared with twohour average BND surface aerosol data centered on the flyby time. This comparison ties the airborne measurements to the surface measurements. Figure $6 a$ and $b$ show comparisons of $\mathrm{AAO}$ and BND submicrometer (aerodynamic diameter) and "total" size fraction aerosol light scattering coefficient data, respectively. In Fig. 6a, since the AAO submicrometer scattering data utilized the $1-\lambda$ nephelometer data at $545 \mathrm{~nm}$, the BND submicrometer data from the $3-\lambda$ nephelometer were adjusted from 550 to $545 \mathrm{~nm}$ using the $450 \mathrm{~nm} / 550 \mathrm{~nm}$ scattering Angström exponent. The plot shows that the measurements for $D_{\mathrm{p}}<1 \mu \mathrm{m}$ particles are quite similar (linear regression slope forced through the origin is $\sim 0.97$ ) for surface and flyby data. The green dashed lines show similar population median values of 24.9 and $26.6 \mathrm{Mm}^{-1}$ for the AAO and BND measurements, respectively. This suggests that for the atmospheric layer between the surface and $\sim 240 \mathrm{~m}$ a.g.l., the aerosol loading of submicrometer particles was similar at least on a statistical basis and that the aircraft inlet efficiently transmitted these particles to the instruments. Figure $6 \mathrm{~b}$ shows for the "total" aerosol population a regression slope forced through the origin has a value of $\sim 0.87$. This suggests that some of the larger particles may not have been sampled by the aircraft instruments and/or that there are real differences in the aerosol loading of larger particles between the surface and $\sim 240 \mathrm{~m}$ a.g.l. The median values for the "total" size fraction comparison are similar at $29.9 \mathrm{Mm}^{-1}$ (AAO) and $31.1 \mathrm{Mm}^{-1}$ (BND). Figure $6 \mathrm{c}$ and d show comparisons of intensive parameters (the $550 \mathrm{~nm} / 700 \mathrm{~nm} \stackrel{\circ}{s}_{\mathrm{s}}$ and $550 \mathrm{~nm} \omega_{0}$, respectively, for the "total" aerosol) measured on both platforms. In Fig. 6c, the median values of 2.04 (AAO) and 2.18 (BND) agree well, and the linear regression forced through the origin (slope of $\sim 0.92$ ) also suggests good agreement between the two sets of measurements. Figure $6 \mathrm{~d}$ shows a noisy relationship between the $\omega_{0}$ measurements at the surface and the flyby altitude, and this is primarily due to larger relative differences in the low $\sigma_{\text {ap }}$ values. The median $\omega_{0}$ values of 0.925 and 0.940 agree well however, and the slope of 0.988 suggests that these two sets of measurements are quite comparable with no major differences observed between surface and the bottom of the lower column. The $\AA_{\mathrm{s}}$ data indicate that for fine particles the surface and profile data sets agree well while the total size fraction data suggest either a very minor problem with the sampling of larger (i.e., supermicrometer) particles or real aerosol particle size differences between the surface and the flyby altitude. While this exercise rules out major sampling problems with the airborne data, determining the potential contribution of each of these factors to the observed comparisons is beyond the scope of this study. Esteve et al. (2012) performed a detailed analysis of the differences observed between the AAO in situ and column (sunphotometer) measurements and have eliminated some of the potential sources of discrepancy from consideration as being negligible.

In order to relate the surface data to the AAO profile data we also compared the lowest flight segments conducted over the BND site with the lowest Lodge profile flight segments. Comparable flight segments from these two data sets were conducted within $15 \mathrm{~min}$ at locations centered $\sim 15 \mathrm{~km}$ away from each other. The same parameters presented in Fig. 6 are compared again in Fig. 7. Excellent agreement is obtained for all extensive and intensive aerosol parameters at this altitude between the two locations; we therefore conclude that the AAO measurements made in the lowest profile flight segment are indeed representative of both the amount and the nature of the aerosol measured at and just above the BND site.

\subsection{Statistical distributions of aerosol properties aloft at low RH}

The statistical distributions of all AAO segment-average profile data (all LODG, TERA, AQB1, AQC1, and AQD1 profiles conducted over the duration of the project) are shown as box-whiskers plots in Fig. 8. In these plots the median of each distribution is shown as a vertical line through the box, the ends of the boxes represent the 25th and 75th percentiles of the distributions, and the ends of the whiskers show the 5th and 95th percentiles. The data shown in Fig. 8 and the other 

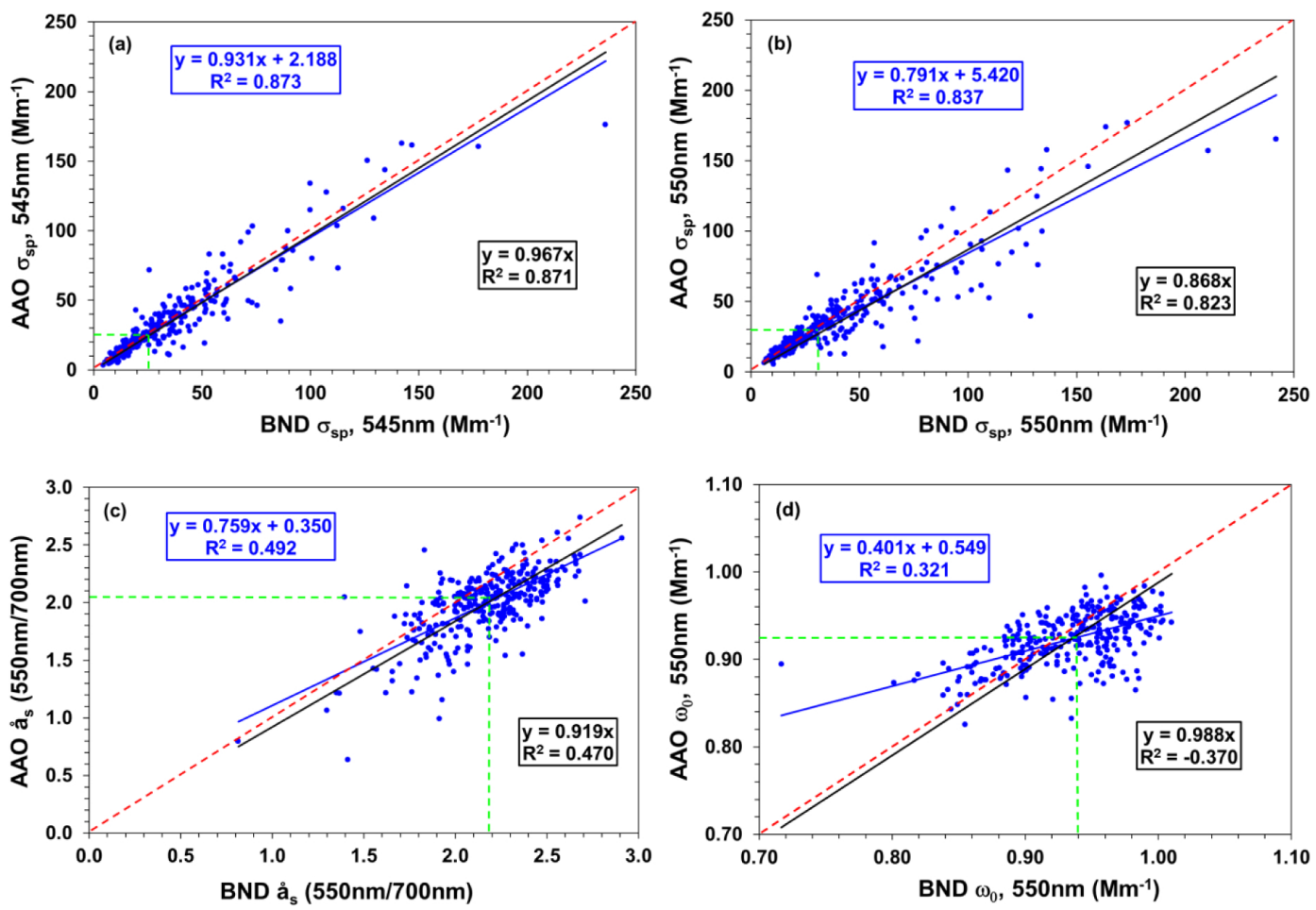

Fig. 6. Comparisons of BND surface aerosol data with concurrent AAO flyby data. Data points represent 5-min AAO low-level flight segment averages over the BND site vs. two-hour BND surface data centered on the flyby time. (a) $\sigma_{\mathrm{sp}}$ for $D_{\mathrm{p}}<1 \mu \mathrm{m}$ particles. (b) $\sigma_{\mathrm{sp}}$ for "total" size cut particles. (c) $\stackrel{\circ}{s}_{s}$ for "total" size cut particles. (d) $\omega_{0}$ for "total" size cut particles. Red dashed line $=1: 1$, green dashed lines show the median values for each population, and blue and black solid lines show the linear regression fit lines (black forced through the origin).

multi-panel figures are from 399 of the 401 research profiles - two flights had power failures prior to reaching the profile location and no profile data were recorded. This represents a retrieval rate of $>99.5 \%$ for the in situ aerosol data from the AAO program. The segment-average data in these plots have been adjusted from instrument conditions to ambient conditions of temperature and pressure, with the exception of the $[\mathrm{CN}]$, which are made using a volume flow rate measured at instrument temperature and pressure. All data reported in Fig. 8 are at instrument conditions of low $(\leq 40 \%)$ RH.

For clarity, only the green wavelength in the multiplewavelength instruments was used for presentation of the statistical distribution plots in Fig. 8, but the spectral dependence of the measurements is shown by the $\stackrel{\mathrm{a}}{\mathrm{s}}_{\mathrm{s}}$ and $\mathrm{a}_{\mathrm{a}}$. Unless otherwise noted, all plotted parameters were calculated from measurements either made at or adjusted to a common wavelength of $550 \mathrm{~nm}$ (the green wavelength of the TSI $3-\lambda$ nephelometer). The PSAP operating wavelength of $530 \mathrm{~nm}$ was adjusted to $550 \mathrm{~nm}$ by log-interpolation between the 530 and $660 \mathrm{~nm}$ wavelengths of the PSAP for calculation of extinction, single-scattering albedo, and radiative forcing efficiency. The wavelength of the $1-\lambda$ nephelometer $(545 \mathrm{~nm})$ was adjusted to $550 \mathrm{~nm}$ using the segment-average $\AA_{\mathrm{s}}$ from the TSI nephelometer $(450 \mathrm{~nm} / 550 \mathrm{~nm})$ for calculation of the $R_{\mathrm{sp}}$. The $\stackrel{\mathrm{a}}{\mathrm{S}}_{\text {data }}$ presented in Fig. 8 were calculated using the 550 and $700 \mathrm{~nm}$ wavelength scattering data from the TSI nephelometer, and the $\stackrel{\circ}{a}_{a}$ data were obtained using all three wavelengths from the PSAP.

Figure 8 shows a clear decrease with altitude of all extensive aerosol parameters (scattering, absorption, extinction, $[\mathrm{CN}])$. The medians of these extensive properties decrease more slowly with altitude above the $1830 \mathrm{~m}$ level, suggesting that the statistical top of the mixed layer for all flights during all seasons is probably near the $1830 \mathrm{~m}$ a.s.l. level. It should be noted again that these flight levels are in fact pressure altitudes and therefore are approximate.

The intensive aerosol properties in Fig. 8 are shown in panels $\mathrm{g}-1$. Because the intensive properties are often ratios of the extensive properties, they can become quite noisy when aerosol extinction is low. For this reason, in this and all other multi-panel figures the intensive properties were limited to those flight segments that exceeded a minimum threshold value of light scattering (segment-average $\sigma_{\mathrm{sp}, 550 \mathrm{~nm}} \geq 3.0 \mathrm{Mm}^{-1}$ under dry $(\leq 40 \% \mathrm{RH})$ conditions $)$. Segments with lower $\sigma_{\mathrm{sp}, 550 \mathrm{~nm}}$ values were excluded from the plotted intensive statistics presented in Figs. 8 through 12. For lower altitude segments (i.e., those conducted at or below the $1520 \mathrm{~m}$ a.s.l. level in the boundary layer), only a few segment-averages from the 399 valid profiles fell below the light scattering threshold. For the higher-altitude flight 

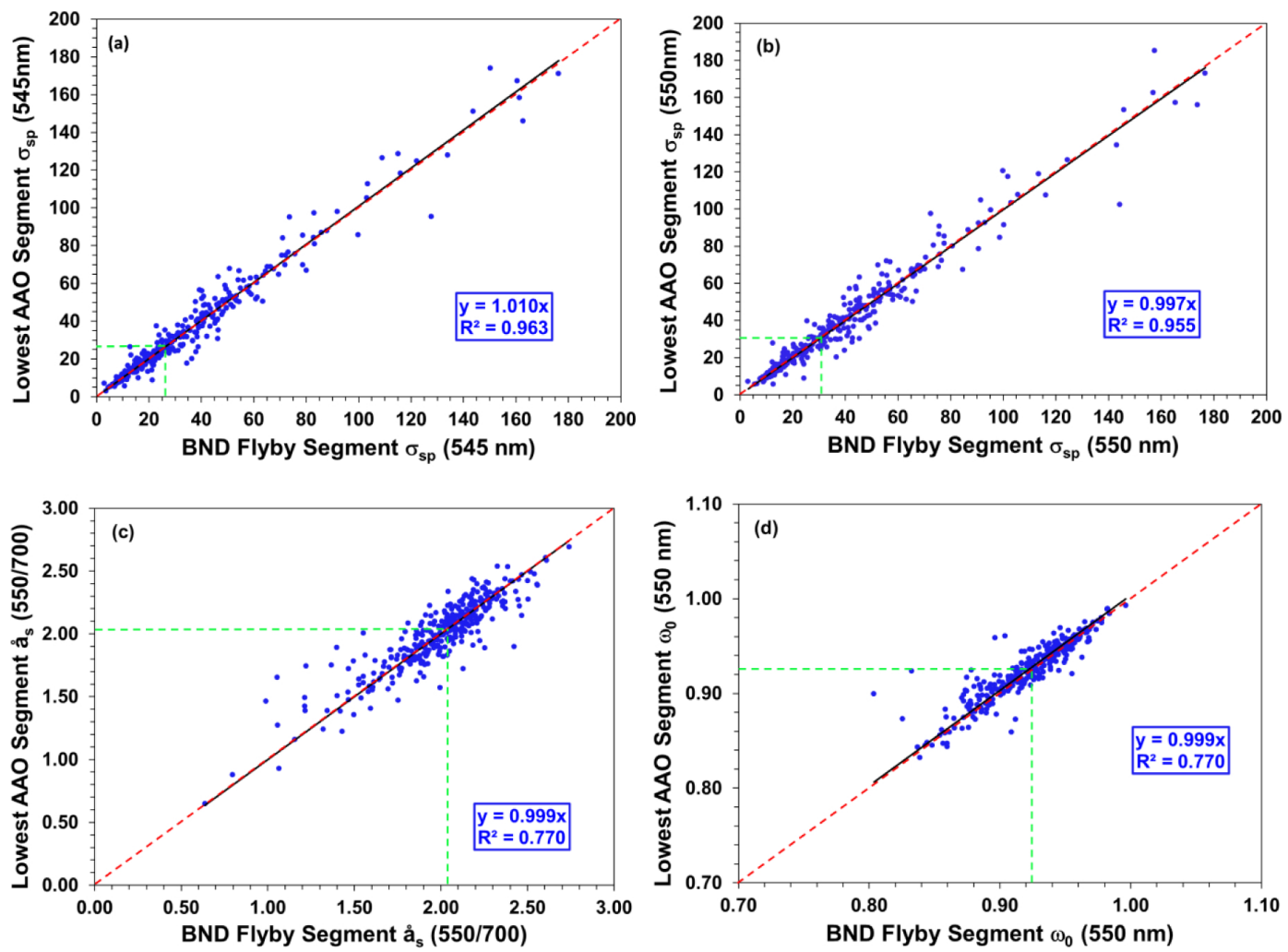

Fig. 7. Comparisons of AAO lowest-segment profile data with BND tower flyby data. Data points represent 5-min flight segment averages of aerosols at the same altitude and displaced by $\sim 15 \mathrm{~km}$. (a) $\sigma_{\mathrm{sp}}$ for $D_{\mathrm{p}}<1 \mu \mathrm{m}$ particles. (b) $\sigma_{\mathrm{sp}}$ for "total" size cut particles. (c) $\stackrel{a}{\mathrm{~s}}_{\mathrm{s}}$ for "total" size cut particles. (d) $\omega_{0}$ for "total" size cut particles. Red dashed line $=1: 1$, green dashed lines show the median values for each population, and black solid line shows the linear regression fit line (forced through the origin).

levels, the exclusion rate ranged from $23 \%$ at $1.8 \mathrm{~km}$ to $59 \%$ at $4.6 \mathrm{~km}$ of the valid flight segments. Our free troposphere (FT) aerosol statistics are therefore biased toward the intensive aerosol properties present during less pristine conditions, and it is unknown how these would compare with the same properties derived during clean conditions.

The intensive properties generally show less variability in the vertical than do the extensive properties, which is broadly consistent with previous studies (e.g., Sheridan and Ogren, 1999; Sheridan et al., 2002; Andrews et al., 2004, 2011). Median $\omega_{0}$ (Fig. $8 \mathrm{~g}$ ) varies from $\sim 0.925$ at the lowest flight level to $\sim 0.94$ at the statistical top of the mixed layer, and stays relatively constant above that. The differences between the median $\omega_{0}$ measurements at low and high altitudes in this study ( $\sim 0.02$, or roughly a few percent relative difference) are within the realm of measurement uncertainty given the estimated total measurement uncertainties in the nephelometer $(\sim 5-10 \%)$ and PSAP $(\sim 10-20 \%)$. Scattering Ångström exponent (Fig. 8j) decreases with altitude above the boundary layer, an observation consistent with the mid-Atlantic coast study of Taubman et al. (2006). Median top of atmosphere (TOA) radiative forcing efficiency (RFE, Sheridan and Ogren, 1999) varies from -25 to $-28 \mathrm{~W} \mathrm{~m}^{-2}$ per unit
AOD throughout the column, indicating that, at least in a statistical sense, the surface measurements can in some cases be used to estimate direct aerosol radiative forcing if a suitable aerosol optical depth measurement is available.

The spectral dependence of aerosol light absorption in the atmosphere depends upon the absorption spectra of the individual aerosol constituents and also their size, shape and/or mixing state (Bergstrom et al., 2007). A larger $\stackrel{\circ}{a}_{a}$ suggests the possibility that organic compounds may be on or in the particles to a larger extent (Kirchstetter et al., 2004; Andreae and Gelenscér, 2006; Bergstrom et al., 2007). Schnaiter et al. (2006) showed that by altering the burn conditions and producing propane soot particles with varying organic/total carbon (OC/TC) ratios, the $\mathrm{a}_{\mathrm{a}}$ varied from near 1.0 at $\sim 8 \%$ OC/TC to $\sim 3.5$ at $\sim 50 \%$ OC/TC. The median $a_{a}$ (Fig. 8k) from the mixed atmospheric aerosols sampled during the AAO program increased from just above 1.0 in the lower portion of the mixed layer to $\sim 1.4$ at the highest flight altitude.

Observations of elevated $\stackrel{a}{a}_{a}$ values are not, however, limited to organic aerosols. Bergstrom et al. (2004), Collaud Coen et al. (2004), and Fialho et al. (2005) discussed the wavelength dependence of absorption for desert dust or 

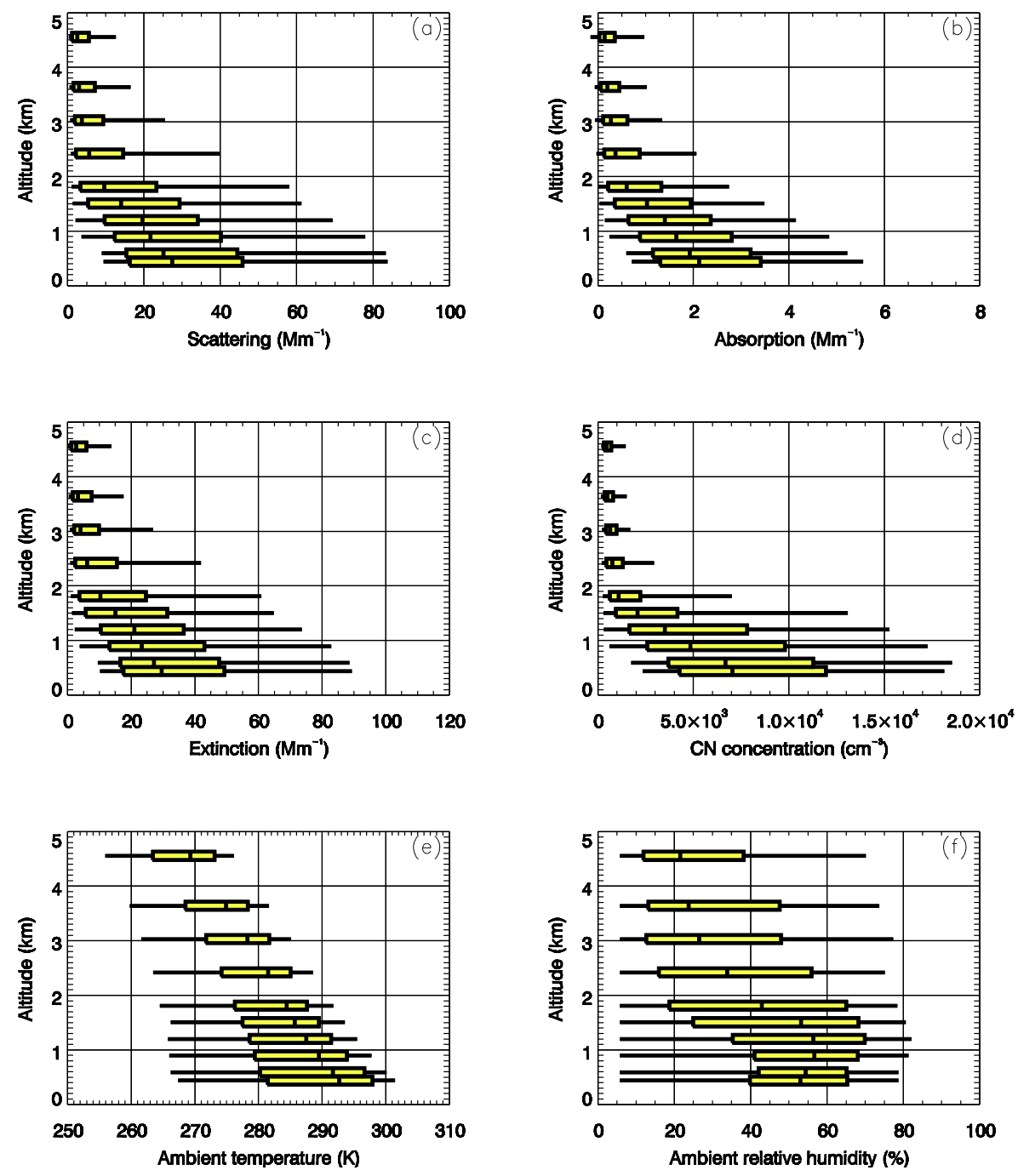

Fig. 8. Cumulative statistics of measured and calculated parameters for all AAO research profiles. Aerosol measurements are for dry $(\mathrm{RH} \leq 40 \%)$ conditions and are adjusted to ambient temperature and pressure, with the exception of the CN concentration, which is reported at instrument temperature and pressure (volume flow rate used).

dust/pollution aerosol mixtures. These studies found elevated $\check{a}_{\mathrm{a}}$ values in the range of 1.5 to nearly 3.0 for aerosol with a significant dust component. We cannot distinguish from the optical measurements whether the observed $\mathrm{a}_{\mathrm{a}}$ values at high altitude are from dust or organic aerosols, or a mixture of both.

The fact that portions of the distributions at all altitudes show $\stackrel{\circ}{a}_{a}$ values less than 1 is interesting given that the theoretical small particle limit for light absorption (spherical particles, constant index of refraction) has been shown to have a $\lambda^{-1}$ dependence (Bergstrom, 1973; Bohren and Huffman, 1983). This could have to do with measurement uncertainties associated with the small light absorption coefficients (the threshold for inclusion of segment averages in the statistics was $\sigma_{\mathrm{sp}, 550 \mathrm{~nm}} \geq 3.0 \mathrm{Mm}^{-1}$, which generally resulted in a $\sigma_{\mathrm{ap}, 550 \mathrm{~nm}}$ threshold of around $0.2 \mathrm{Mm}^{-1}$ - this threshold may be too low for practical calculation of $a_{a}$ ). It could however be partially explained by the fact that the imaginary part of the index of refraction increases slightly with wavelength for some types of particles and this could cause the $\mathrm{a}_{\mathrm{a}}$ to dip below the theoretical limit of 1.0 (Bond and Bergstrom, 2006, and references therein).

The profiles of $R_{\mathrm{sp}}, b$, and $\AA_{\mathrm{s}}$ all suggest that there is a larger relative contribution to scattering extinction from larger particles with increasing height above the surface up to $4.6 \mathrm{~km}$. This could be explained by more sources of small particles (e.g., combustion aerosols, photochemical smog) at the surface, long-range transport of supermicrometer particles aloft, or selective wet scavenging processes at altitude. Less-hygroscopic aerosols may have different size distributions than water-absorbing aerosols or may contain a larger fraction of OC, and organic aerosols have been shown 

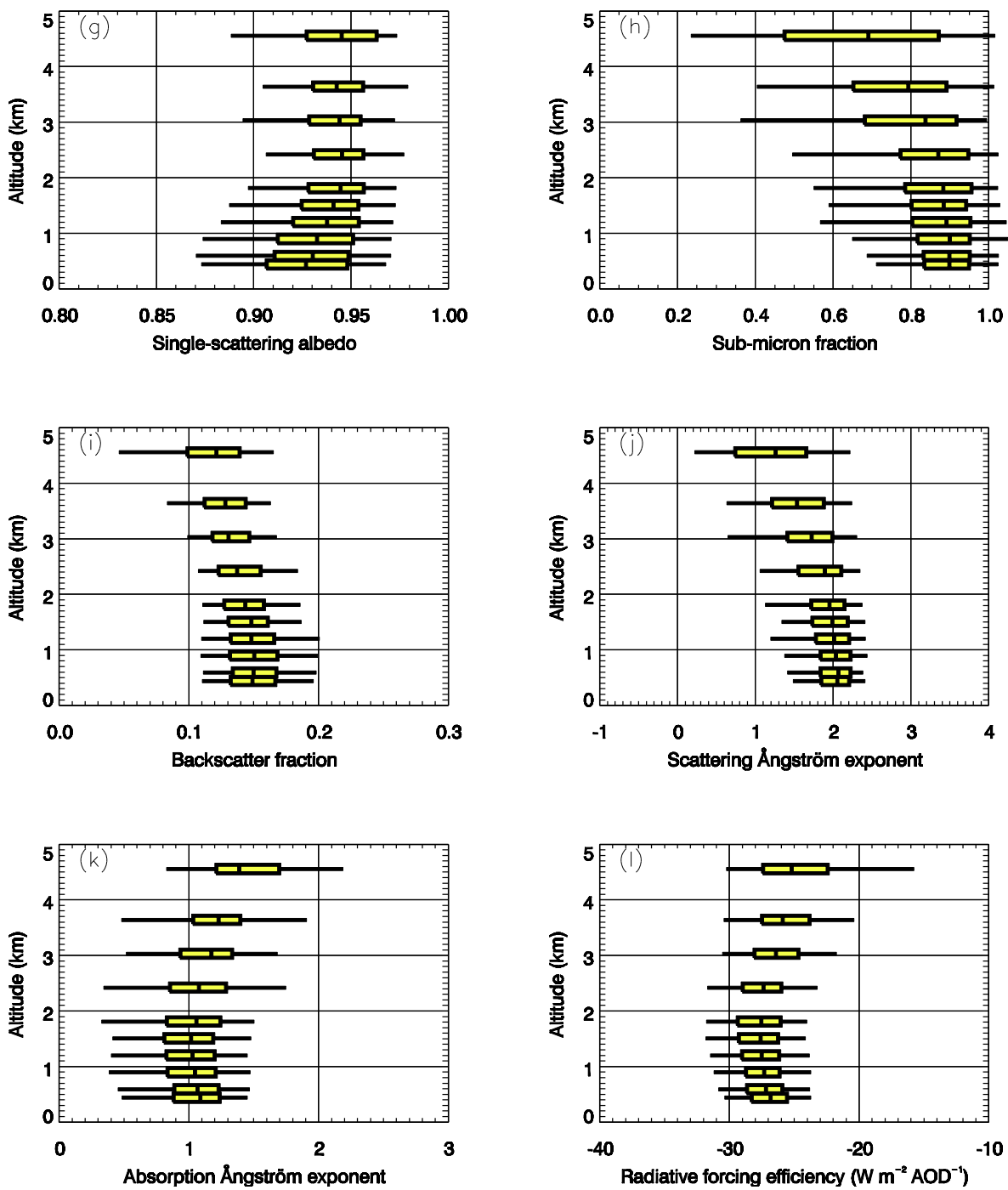

Fig. 8. Continued.

to resist wet removal processes (McFiggans et al., 2006; and references therein). Similarly, uncoated dust or dust coated with organics would presumably not be very hygroscopic and could remain aloft for extended periods.

The in situ aircraft data for the statistical distributions of aerosol properties presented in Fig. 8 have been plotted in time-altitude space in Fig. 9. These contour plots show how the aerosol properties vary with altitude over the duration of the AAO program. In these plots, individual flight segments are represented as black dots, and the segment-average values for each parameter have been contoured. The variation in sampling altitudes is caused by a seasonal variation in the relationship between pressure and geometric altitudes. The extensive parameters (Fig. 9a-d) show a wavelike pattern, with relatively larger values of these parameters extending to higher altitudes in the summertime. This may be because of the increased height of the top of the mixed layer during the warmer months due to enhanced vertical mixing, significant seasonal increases in the aerosol sources (primary and/or secondary) beginning in the spring and lasting through fall, and/or fewer or less efficient removal mechanisms at work during this period.

The annual ambient temperature and $\mathrm{RH}$ cycles are shown in Fig. 9e and f, respectively. A $\sim 4$ month gap in the ambient RH, from late 2006 through early 2007 was caused by a malfunctioning RH sensor. As in Fig. 8, the intensive parameters have been plotted in panels $9 \mathrm{~g}-1$, with the same noise-filtering threshold of segment-average $\sigma_{\mathrm{sp}, 550 \mathrm{~nm}} \geq 3.0 \mathrm{Mm}^{-1}$. Panel $9 \mathrm{~g}$ shows a weak annual cycle in $\omega_{0}$, with the lowest values in the boundary layer in the fall. This supports the September-October minimum in the longterm $\omega_{0}$ record observed at the Bondville surface monitoring site (Delene and Ogren, 2002), as well as the similar fall $\omega_{0}$ minimum at the mid-continental SGP site (Sheridan et al., 


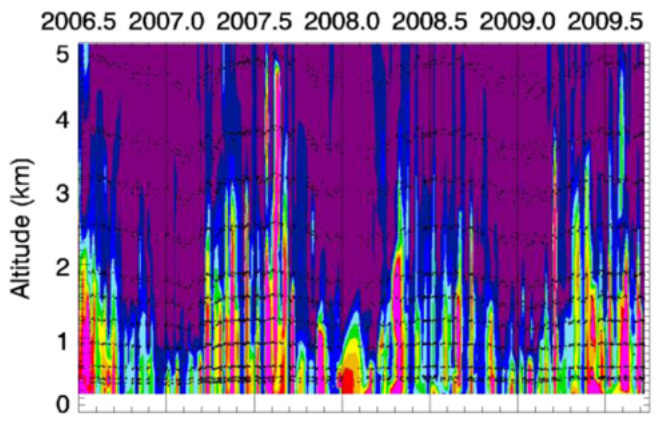

2006.52007 .02007 .52008 .02008 .52009 .02009 .5

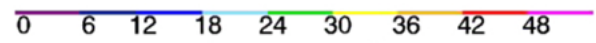
(a) Scattering $\left(\mathrm{Mm}^{-1}\right)$

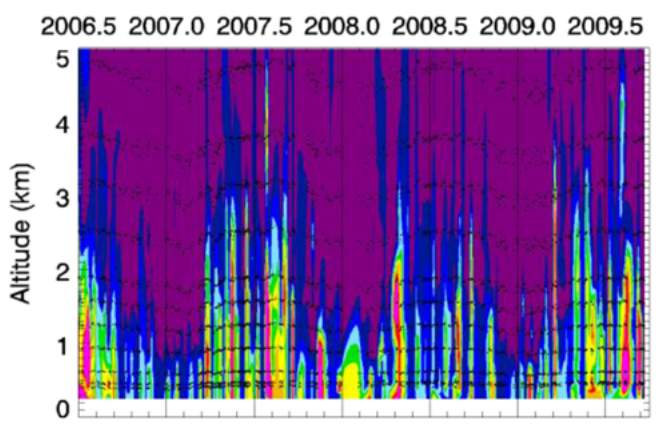

2006.52007 .02007 .52008 .02008 .52009 .02009 .5

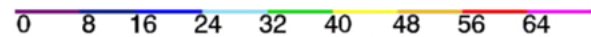

(c) Extinction $\left(\mathrm{Mm}^{-1}\right)$

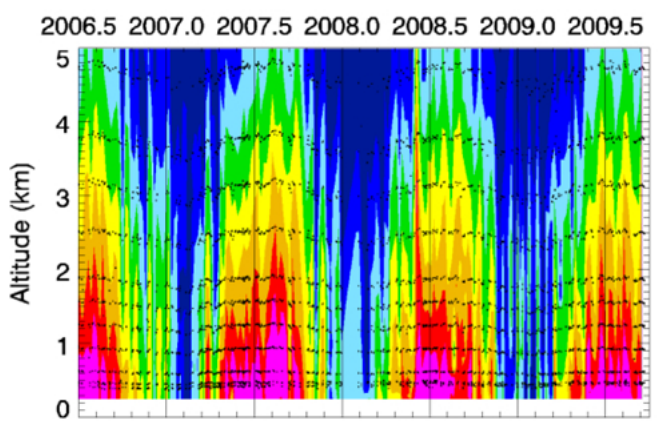

2006.52007 .02007 .52008 .02008 .52009 .02009 .5

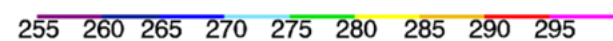

(e) Ambient temperature $(\mathrm{K})$

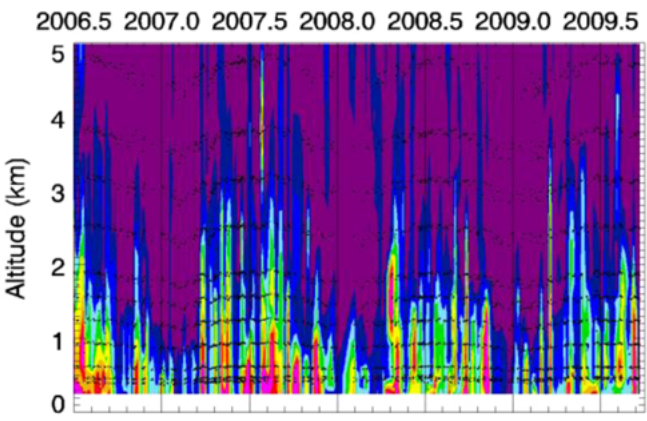

2006.52007 .02007 .52008 .02008 .52009 .02009 .5

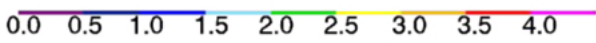

(b) Absorption ( $\left.\mathrm{Mm}^{-1}\right)$

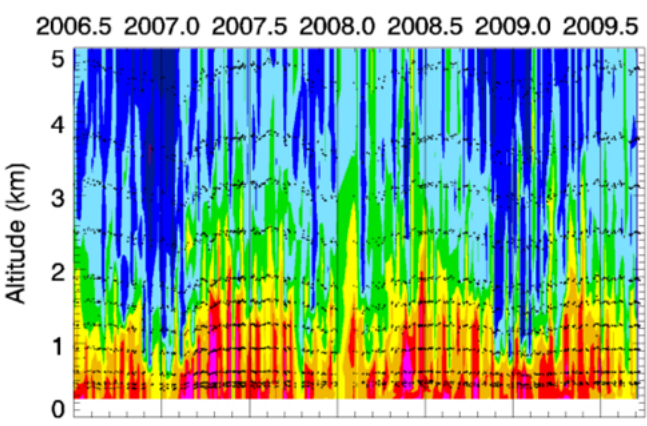

2006.52007 .02007 .52008 .02008 .52009 .02009 .5

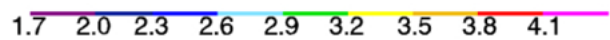

(d) Log $\mathrm{CN}$ concentration $\left(\mathrm{cm}^{3}\right)$

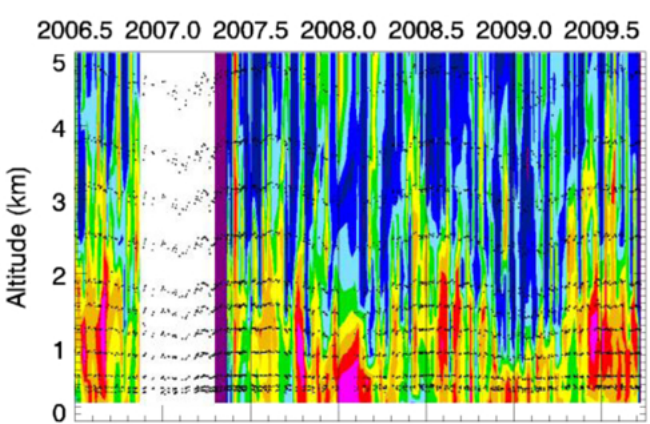

2006.52007 .02007 .52008 .02008 .52009 .02009 .5

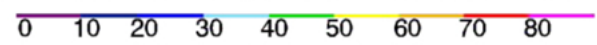

(f) Ambient relative humidity (\%)

Fig. 9. Time series contour plots of AAO measurements. Black dots represent individual flight segments.

2001). Consistent with Fig. 8, the data displayed in panels $9 \mathrm{~h}-\mathrm{j}$ suggest that larger particles have a greater influence on the aerosol optical properties at higher altitudes.

The contour plots of intensive properties show an anomalous high altitude feature in early 2009 that is visible in the upper right portion of most of the panels. Panels $9 \mathrm{~h}-\mathrm{j}$ suggest that larger particles were present at this time, and $\omega_{0}$ was higher than typical, with values exceeding 0.94 . Overall RFE was lower than that typically observed for this program at $<-25 \mathrm{~W} \mathrm{~m}^{-2}$. Larger, mostly scattering aerosols at higher altitudes could be long-range intercontinental trans- port of Asian dust and/or pollution or aged biomass smoke advecting over the central US during the springtime (VanCuren, 2003; Augustine et al., 2008). The springtime Asian aerosol, which has both a dust and pollution component, has been shown to stay aloft for very long periods of time and to travel great distances (Rahn et al., 1977).

Median profiles of aerosol properties segregated by season are shown in Fig. 10. Seasons are described here according to the conventional three-month definitions of spring = MAM, summer $=\mathrm{JJA}$, fall $=\mathrm{SON}$, and winter $=\mathrm{DJF}$. In all plots, colored lines show the spring, summer, fall, and winter 


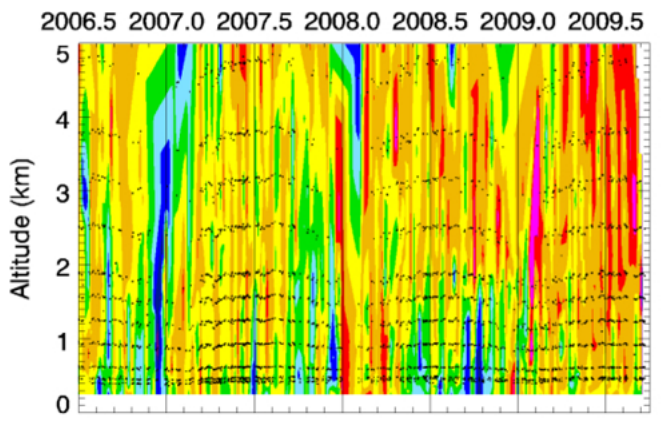

2006.52007 .02007 .52008 .02008 .52009 .02009 .5

$\begin{array}{lllllllll}0.82 & 0.84 & 0.86 & 0.88 & 0.90 & 0.92 & 0.94 & 0.96 & 0.98\end{array}$

(g) Single-scattering albedo

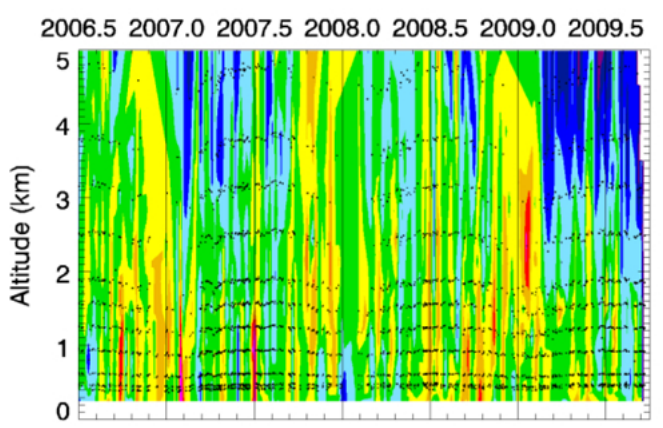

2006.52007 .02007 .52008 .02008 .52009 .02009 .5

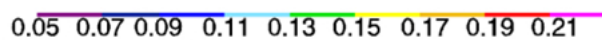

(i) Backscatter fraction

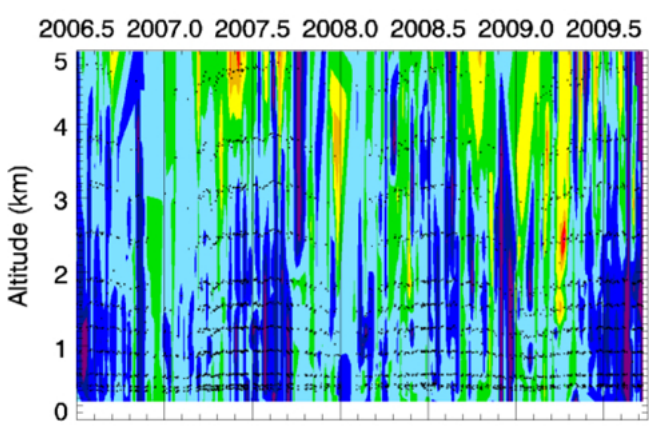

2006.52007 .02007 .52008 .02008 .52009 .02009 .5

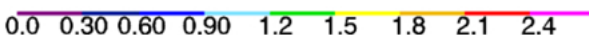

(k) Absorption Ångström exponent

Fig. 9. Continued

median profiles along with the black annual median profile. Black horizontal lines show the extent of the 25th and 75th percentiles of the annual distributions. The seasonal plots for the extensive properties confirm that for most of the sampled vertical column, the largest aerosol loadings over the BND site were in the summer season and the lowest were during the winter. Above $3 \mathrm{~km}$ a.s.l., the median spring extinction values exceeded those for all other seasons. This suggests the occasional presence of elevated aerosol layers in the springtime over the BND site. When interpreted in conjunction with the contour plots, these data suggest that springtime

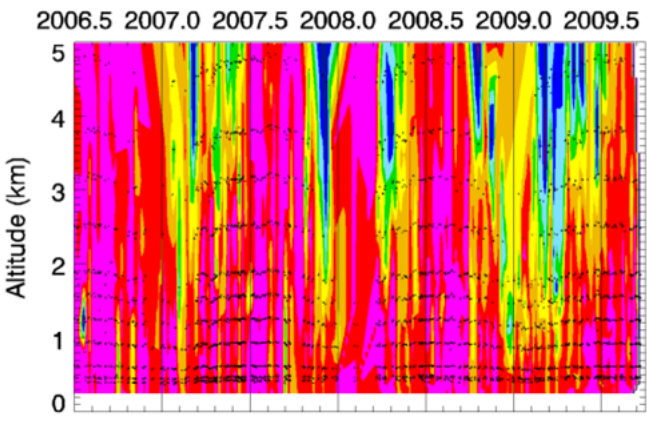

2006.52007 .02007 .52008 .02008 .52009 .02009 .5

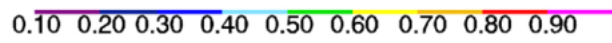
(h) Submicron scattering fraction
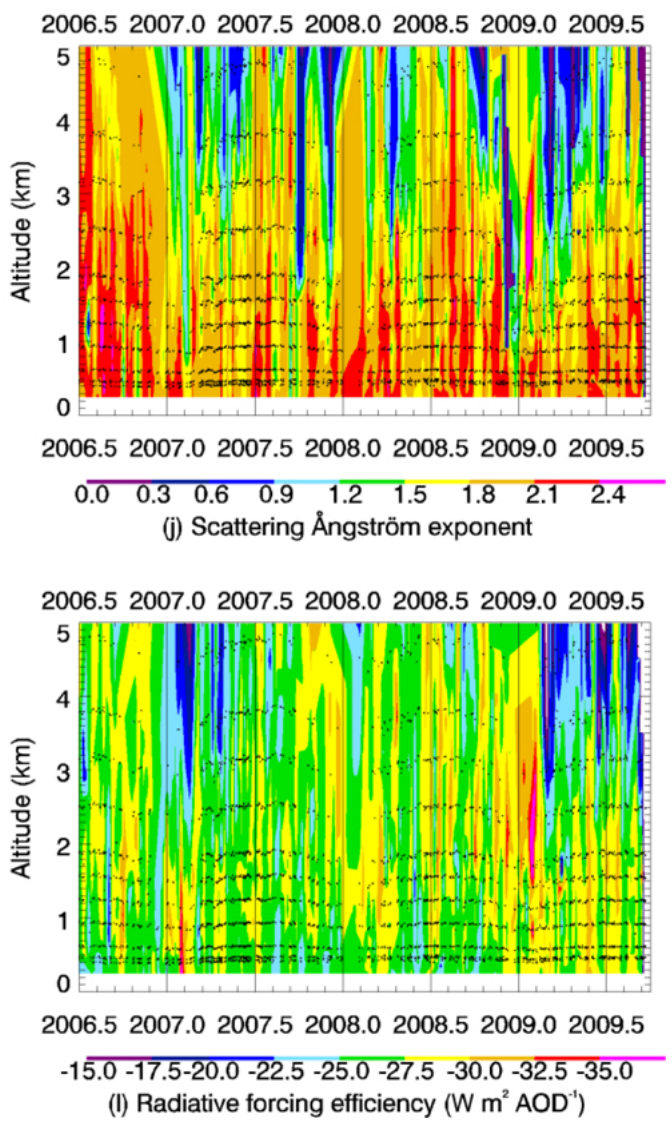

aerosol incursions at high altitude over central Illinois are infrequent and episodic in nature rather than a regular event each spring.

The seasonal plot of $\omega_{0}$ supports the contour data presented in Fig. 9. The lowest $\omega_{0}$ values at low altitude appear in the fall, and the seasonal values generally fall between $\sim 0.92-0.95$. The wintertime 3.0 and $3.7 \mathrm{~km}$ levels show slightly larger $\omega_{0}$ median values of $\sim 0.96$, but this may be an artifact of the limited sample population. Fewer than $25 \%$ of the 65 wintertime flight segments at these high altitudes exceeded the $\sigma_{\mathrm{sp}, 550 \mathrm{~nm}}$ threshold value. Panels $10 \mathrm{~h}-\mathrm{j}$ 

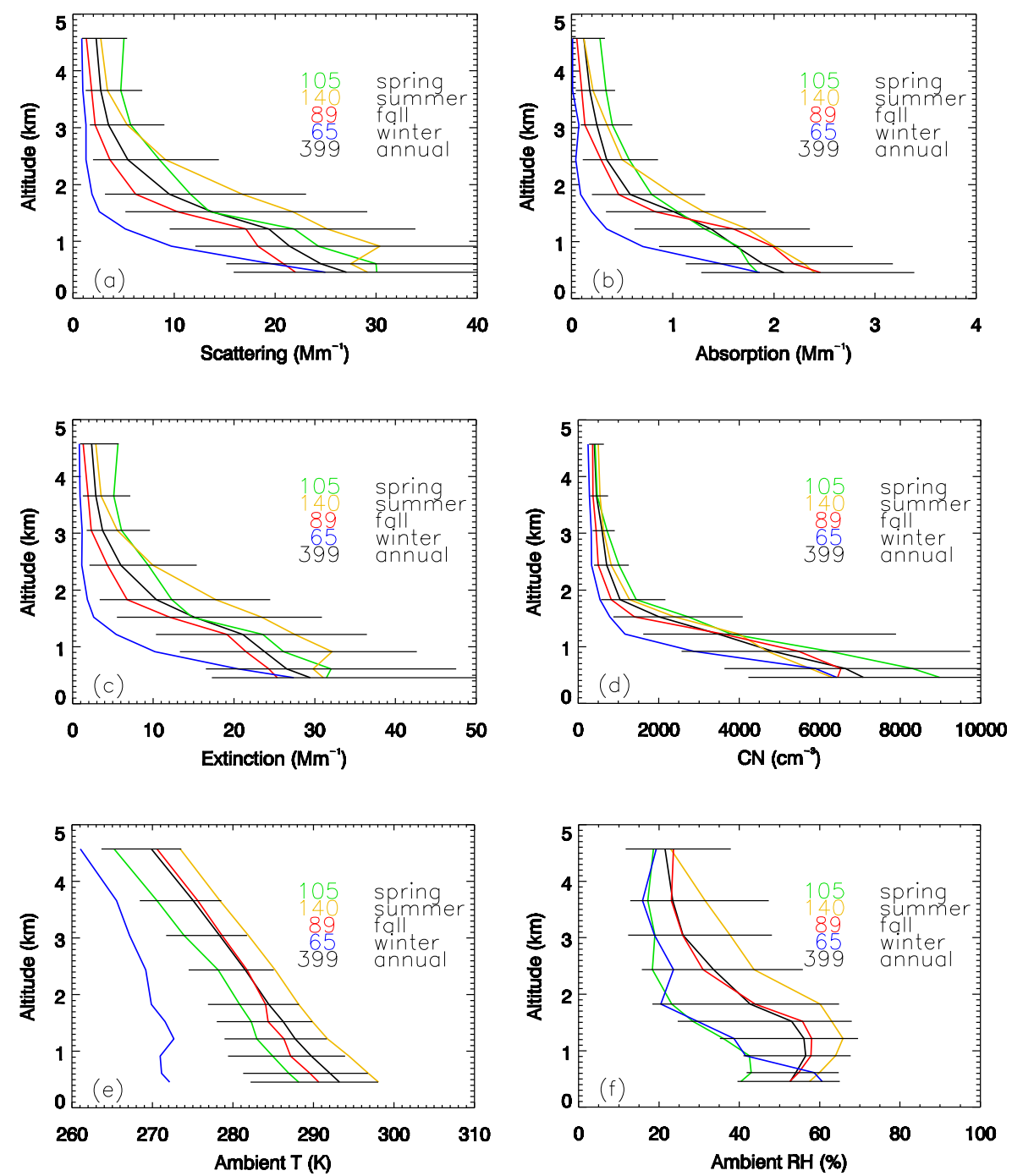

Fig. 10. Median seasonal profile plots of AAO measurements. Black profile in each plot represents all aircraft profiles. Horizontal bars show the extent of the 25 th and 75 th percentiles of the total distribution.

show the general trends of decreasing $R_{\mathrm{sp}}, b$, and $\AA_{\mathrm{s}}$ with increasing altitude, consistent with the presence of larger particles at higher altitudes.

Cumulative seasonal plots of the median scattering, absorption, and extinction (all at $550 \mathrm{~nm}$ ), and $[\mathrm{CN}]$ are presented in Fig. 11. These plots of the extensive parameters show the percentage of the total column amount of each parameter that occurs below a given altitude in the atmospheric column from the surface to $4.6 \mathrm{~km}$. For example, the cumulative extinction plot shows that for all seasons $\sim 80 \%$ of the extinction in the column is observed at or below $1.8 \mathrm{~km}$ altitude, while in the winter $\sim 90 \%$ of the column extinction is below that altitude. In general, winter observations show that a larger fraction of the total column aerosol is present at lower altitudes than during the other seasons. This is probably because of the lower mixed layer heights in the winter over this site. The green lines representing spring medians lie above the other seasonal lines for scattering, absorption and extinction, and can probably be explained by the fact that high altitude ( $3 \mathrm{~km}$ altitude and above) aerosol layers were present more frequently during the springtime, so that a smaller percentage of the total column abundance of these parameters exists at the lower altitudes. These higher median values can be seen clearly in the seasonal profile plots in Fig. 10.

\subsection{Aerosol scattering hygroscopic growth measurements}

Over the first two years, we had difficulty for a variety of reasons in running the humidified nephelometer system. These problems included intermittent electrical power and signal connections, drifting calibrations, overnight cold-soaking of 

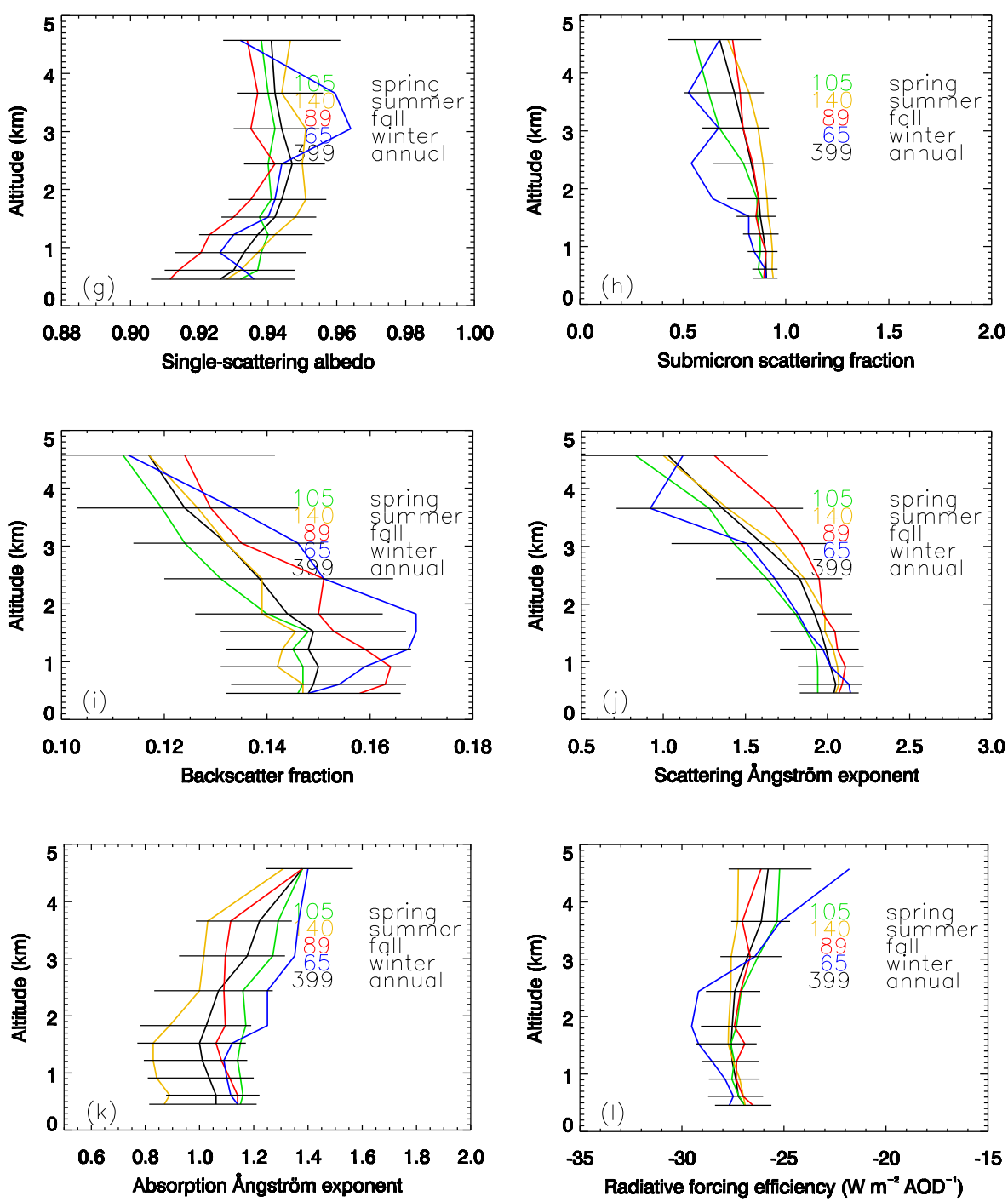

Fig. 10. Continued.

the humidifiers and nephelometers (leading to water freezing in the system and ruptured humidifier membranes), and an inability to accurately control the internal RH of the humidified nephelometers at their respective set points which led to condensation of water vapor inside the instruments. Our program was designed to have a pilot fly an automated airborne aerosol system and do very limited pre-flight work, so many of these problems, including the drifting calibrations, were not fixable without service visits. The problem of proper control of the nephelometer internal RH was finally solved late in the program by our development of custom, real-time software PID control. Hygroscopic growth data for the early flights is not retrievable.

Valid aerosol hygroscopic growth data were first obtained in the fall of 2008. During this period the hardware issues were gone but the problem of drifting calibrations for the humidified nephelometers remained. We visited the AAO sev- eral times over this year and recalibrated the instruments, and typically flew one to several flights before the calibrations drifted to outside acceptable limits. For unknown reasons, these calibration drifts were not gradual but relatively large step changes between flights. Over the last year of the project we obtained $f(\mathrm{RH})$ data from 12 profiles where calibrations were good (based on frequent calibration checks) and all nephelometers were functioning properly. These data are shown in Fig. 12. As with the other intensive measurements, the reported hygroscopic scattering growth data were limited to segments where the segment-average, dry $\sigma_{\mathrm{sp}, 550 \mathrm{~nm}}$ was $\geq 3.0 \mathrm{Mm}^{-1}$; this limited the data to 80 total flight segments at the various altitudes. This constraint significantly reduced the number of valid high-altitude segments we report but should reduce the statistical uncertainty inherent in ratios of very small numbers. Figure 12 illustrates that the distributions of $f(\mathrm{RH})$ and $\gamma$ in the FT are clearly different from 

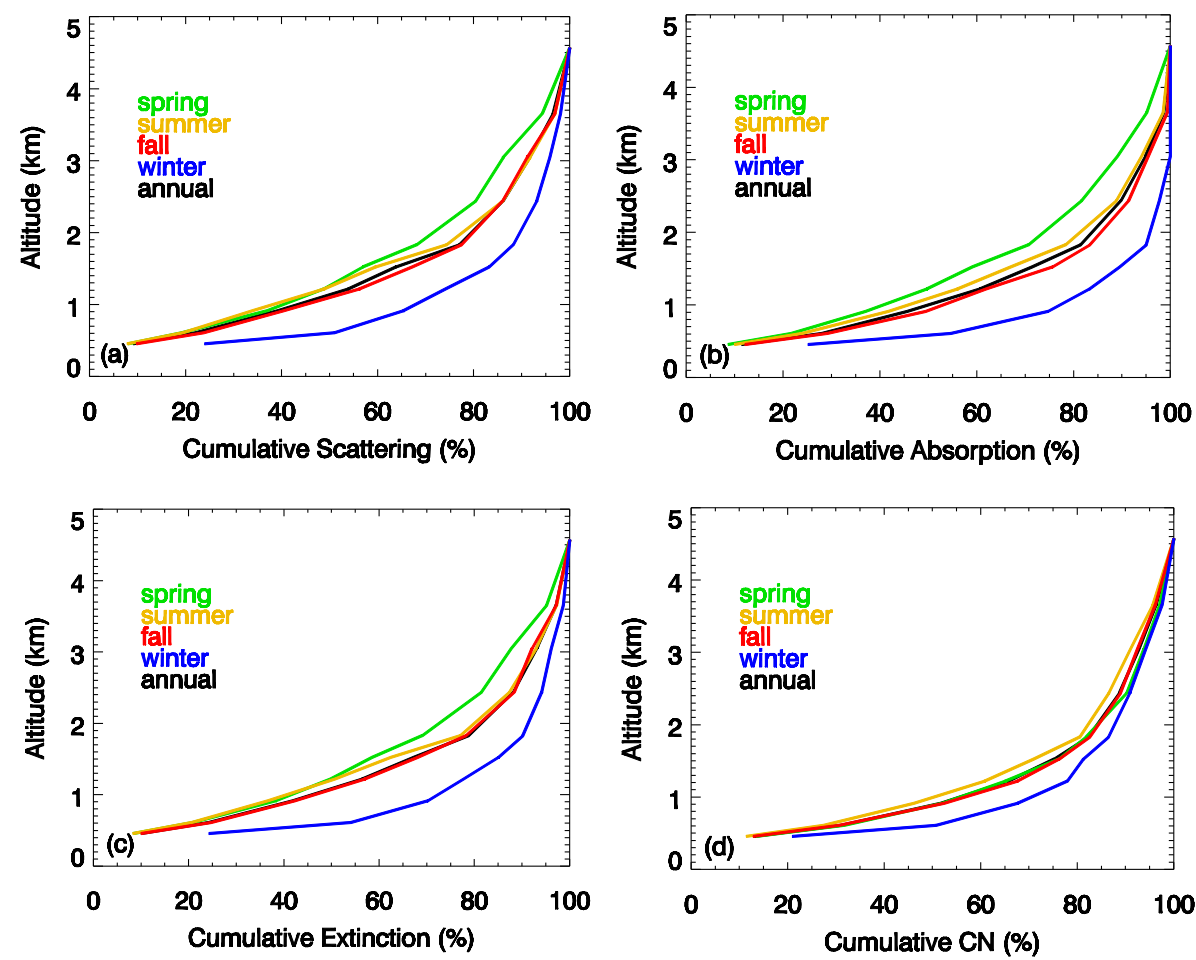

Fig. 11. Seasonal median plots showing the cumulative percentage of each extensive parameter in the lower atmospheric column (surface to $4.6 \mathrm{~km}$ a.s.1.) that occurs at or below a given altitude.

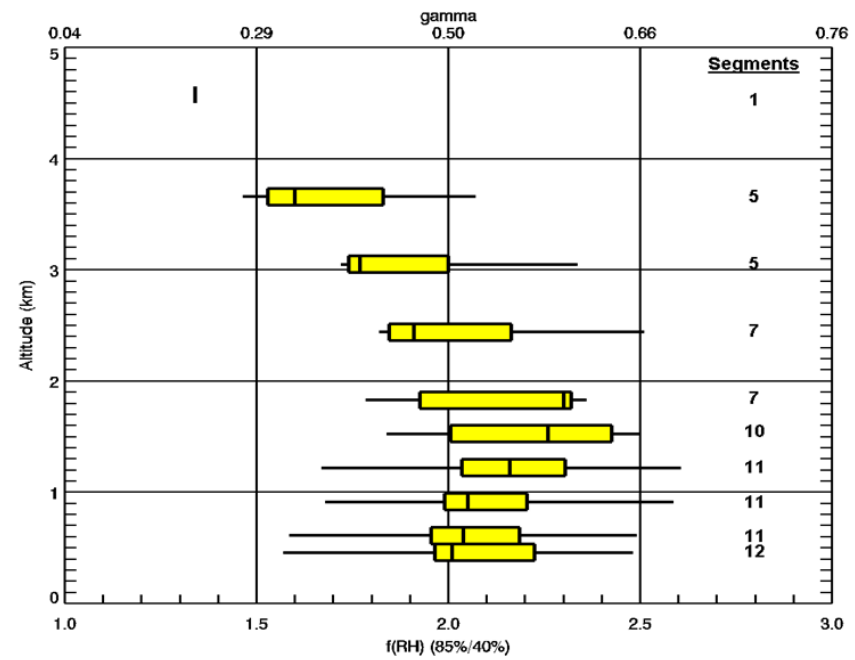

Fig. 12. Cumulative profile plot of the statistical distributions of $f(\mathrm{RH})$. The number of flight segments at each altitude that comprise the distributions is shown at right. The gamma values were derived by fitting curves as described in Table 2 to the humidified nephelometer measurements. The $f(\mathrm{RH})$ is the scattering hygroscopic growth factor from 40 to $85 \% \mathrm{RH}$.

those in the planetary boundary layer (PBL, $\leq \sim 1.8 \mathrm{~km}$ a.s.l. in the profiles shown in Figs. 8 and 10), with the lower values $(f(\mathrm{RH})<2.0)$ observed in the FT. This could be because of surface sources of hygroscopic particles and/or because of the role cloud-processing plays in removing a fraction of the more hygroscopic material at the higher altitudes, leaving behind an aerosol enriched in less hygroscopic particles (e.g., Weingartner et al., 1999; Marcq et al., 2010; Berkowitz et al., 2011).

Esteve et al. (2012) have already presented a detailed discussion on the limited AAO $f(\mathrm{RH})$ measurements and their comparison with previous hygroscopic growth studies at BND so only a brief synopsis is presented here. Aerosol chemistry data from selected periods during the KoloutsouVakakis et al. (2001) study period yielded a $\gamma$ value of 0.67 by utilizing the Quinn et al. (2005) parameterization for $f(\mathrm{RH})$, which is based on the relative amounts of particulate organic matter and sulfate in the aerosol. A $\gamma$ of 0.67 results in an estimated $f(\mathrm{RH})$ (at $82.5 \% \mathrm{RH}$ ) of 2.28 using the Quinn et al. (2005) parameterization, which is higher than the $f(\mathrm{RH})$ value of 1.5 (effective $\gamma=0.33$ ) derived from the humidified nephelometry measurements of Koloutsou-Vakakis et al. (2001). Note that the Koloutsou-Vakakis $f(\mathrm{RH})$ measurements were based on a high-RH scattering measurement at $82.5 \%$, which is slightly lower than the $85 \%$ employed in this study. Independent aerosol chemistry data from the IMPROVE (Interagency Monitoring of PROtected Visual Environments) network site at BND between January 2006 and December 2008 also gives a $\gamma$ value of $0.67(f(\mathrm{RH})=2.28)$ using the Quinn et al. (2005) parameterization. A median $\gamma$ 


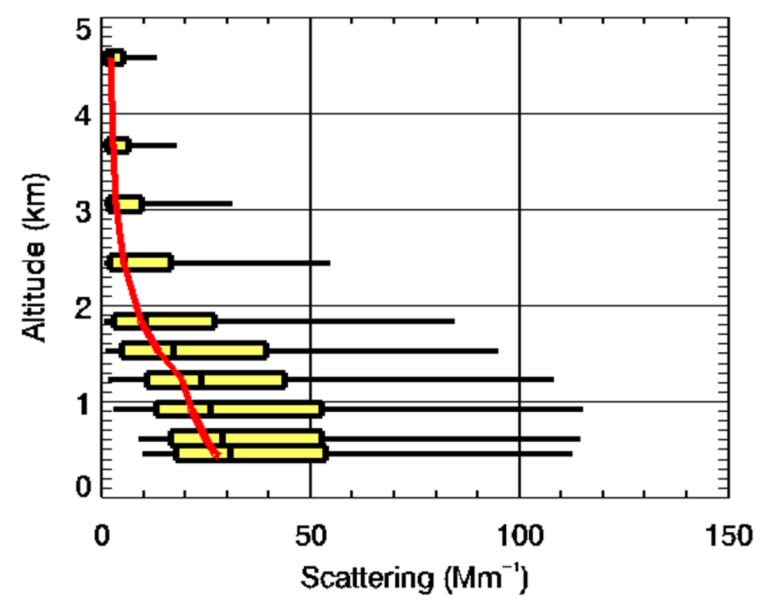

Fig. 13. Cumulative box/whiskers plot of AAO aerosol light scattering profile data adjusted to ambient $\mathrm{RH}$. Individual segment average scattering data were adjusted using the median $\gamma$ value at each altitude from Fig. 12 and the segment average RH. Red line represents the median dry values from Fig. 8a.

value of 0.51 for the AAO aircraft measurements was derived by fitting curves as described in Table 2 to the humidified nephelometer measurements from the 80 valid AAO flight segments where all humidified nephelometers were working properly. This value of $\gamma$ results in an estimated $f(\mathrm{RH})($ at $85 \% \mathrm{RH})$ of 2.03 , intermediate to the values derived from the chemical composition and Koloutsou-Vakakis approaches (Esteve et al., 2012). For comparison, the median boundary layer (all flight segments conducted below $\sim 1.8 \mathrm{~km}$ altitude) $\gamma$ value was $0.53(f(\mathrm{RH})=2.08)$ and the median free troposphere (all flight segments above $\sim 1.8 \mathrm{~km}$ altitude) $\gamma$ value was $0.44(f(\mathrm{RH})=1.84)$.

The cumulative dry aerosol $\sigma_{\mathrm{sp}}$ distributions shown in Fig. 8 were adjusted to ambient $\mathrm{RH}$ and are presented in Fig. 13. Individual flight segment-average $\sigma_{\mathrm{sp}}$ values at $550 \mathrm{~nm}$ were adjusted to ambient $\mathrm{RH}$ using the median altitude-specific $\gamma$ value for all valid segments and the segment-average RH. The median $\gamma$ value for each flight level was used because so few flight segments were conducted with valid hygroscopic growth measurements. It is implicit in this analysis that the median $\gamma$ values at each flight altitude adequately represent the hygroscopic growth characteristics of the aerosols during flights when the humidified nephelometry system was not working properly. We observed no obvious long-term changes in aerosol characteristics over the duration of the program to lead us to believe that this assumption was not valid. Additionally, the segmentaverage RH was typically low enough that small to moderate changes in the $\gamma$ parameter would not result in major changes in the adjusted $\sigma_{\mathrm{sp}}$ values.

Even though the adjustment of scattering to ambient RH is nonlinear in $\mathrm{RH}$, we felt using the segment average rather than the instantaneous RH was appropriate for two reasons.
First, the RH measured on most of our flight segments was not very high, and RH variability at lower RH does not cause large changes in the optical properties. Figure $8 \mathrm{f}$ shows that median RHs for flight segments in the mixed layer were 50$60 \%$ and were lower at higher altitudes. Only a small fraction of all flight levels show segment-average $\mathrm{RH}$ values at or above $70 \%$, where the growth function becomes steeper. Secondly, RH variability was consistently small over the 5 and 10 min horizontal segments flown over the course of the program. Considering all AAO flight segments, the average standard deviation (SD) of RH measurements during individual flight segments was $2 \%$ (with a SD of the SD values of $\pm 2 \%$ ). That is, on average, each AAO flight segment showed a relatively small variability (expressed as the SD) of $2 \% \mathrm{RH}$. While there were a few flight segments conducted at higher RH that also showed a larger RH variability, this was not a commonly observed feature of the data set.

In general, the changes from the dry scenario for light scattering shown in Fig. 13 are relatively small, with median ambient scattering values in the PBL higher than the dry case (dry median values shown by red line) by only a few $\mathrm{Mm}^{-1}$. This can be explained by the fact that flights typically occurred during sunny to partly cloudy conditions where ambient RH was relatively low (typically $<60 \%$ ). Figure 10 f shows that even during the summer, median RH's in the PBL during AAO flights were $\sim 57-65 \%$. Relative humidities in this range are not high enough to dramatically increase the dry scattering values. No attempt was made to scale AAO light absorption data (or single-scattering albedo and extinction data) due to a lack of information on the hygroscopic growth function for $\sigma_{\mathrm{ap}}$. The in situ AAO extinction measurements used for comparison with the satellite-derived extinction reported below have thus had their scattering component adjusted to ambient RH conditions while the absorption component was held at low RH conditions. These in situ measurements therefore most likely represent a lower limit to the true $\sigma_{\mathrm{ep}}$ values at ambient $\mathrm{RH}$, assuming $\sigma_{\mathrm{ap}}$ increases with increasing RH. Since RH was not high in most flight segments and since $\sigma_{\mathrm{ap}}$ is usually a small fraction of $\sigma_{\mathrm{ep}}$, the reported AAO $\sigma_{\mathrm{ep}}$ values should be close to the true ambient values.

\subsection{Satellite vs. in situ extinction comparisons}

One of the objectives of this program was to obtain in situ aerosol data during satellite overflights for potential satellite retrieval verification. The AAO $\sigma_{\text {ep }}$ data used in all comparisons with the CALIPSO lidar have been adjusted as discussed above to ambient conditions of $T, p$, and $\mathrm{RH}$ to the extent possible for these comparisons. The scattering component of AAO extinction for each comparison was adjusted to ambient RH utilizing the median $\gamma$ value for that specific altitude, and was then adjusted to the $532 \mathrm{~nm}$ wavelength of the CALIPSO lidar based on the $450 / 550 \mathrm{~nm} \stackrel{a}{s}_{\text {. The }}$ absorption component of AAO extinction was not adjusted to 
ambient RH given the lack of understanding of the RHdependence of $\sigma_{\mathrm{ap}}$ in ambient aerosols. The in situ absorption measurement was adjusted to the lidar wavelength using the $530 \mathrm{~nm} / 660 \mathrm{~nm} \stackrel{a}{a}_{\mathrm{a}}$.

The three primary AAO profile locations were chosen to be within $10 \mathrm{~km}$ of three A-Train satellite tracks (Fig. 3), and as shown in Fig. 7 and reported in Anderson et al. (2003), the aerosol properties are expected to be similar over this distance. Over the course of the program 63 AAO flights were conducted at these locations where the aircraft was in the PBL within two hours of the CALIPSO satellite overpass. It is reasonable to ask whether there were any systematic differences between the aerosol properties measured during the satellite and non-satellite flights. One could surmise that, since the satellite underflights were constrained operationally to occur on less cloudy days, the aerosol properties could be different in drier conditions. It was observed, however, that there were not major statistical differences in either the extensive or intensive aerosol properties between flights with and without satellite overpasses. For example, the median AAO-measured $\sigma_{\mathrm{ep}}$ and $\omega_{0}$ values (at $550 \mathrm{~nm}$ ) measured during the 63 overpass flights at the five segment altitudes in the boundary layer agreed to within $2 \mathrm{Mm}^{-1}$ and 0.005 , respectively, with the analogous measurements from the 336 non-overpass flights.

CALIPSO Level 2 aerosol extinction profiles are retrieved based on 5,20 , and $80 \mathrm{~km}$ horizontal averages of total attenuated backscatter and are reported every $5 \mathrm{~km}$ along the track at $60 \mathrm{~m}$ vertical resolution. The comparisons with in situ aerosol extinction are based on the AAO measurement being matched with the CALIPSO retrieval from the closest 60-m range bin to the mean flight segment altitude. For this comparison, 35-km (i.e., 7 extinction profiles) along-track averages centered on the closest profile were used so that the satellite would sample a similar airspace as the airplane. We initially analyzed the CALIPSO data both using 180 -m vertical averaging and also with no averaging, and the profile statistics did not change very much. We decided not to average vertically to avoid incorporating aerosol not observed by the aircraft into CALIPSO profile data, but acknowledge that layer heights may change by $120-180 \mathrm{~m}$ over a distance of $35 \mathrm{~km}$. As discussed below, this is not believed to be a prevalent feature in this data set.

CALIOP lidar aerosol extinction data (Level 2 Aerosol Profile Product, Version 3.01 processing) were retrieved for 28 of the 63 collocated profiles. CALIPSO data are qualityscreened based on metrics used to generate CALIPSO Level 3 aerosol profile products from Level 2 aerosol extinction data (Winker et al., 2012) and are described in Appendix A. Quality screening removed approximately $4 \%$ of all possible collocated CALIPSO extinction samples. "No retrieval" cases most likely mean that it was either too cloudy, there was not enough aerosol present, and/or there was too much noise in the daytime CALIPSO profile to retrieve extinction at the resolution required. Inspection of the CALIPSO browse images (using the vertical feature mask) revealed that for some of these 35 "no retrieval" cases, CALIPSO detected aerosols farther away from the aircraft profile location but not within the $35-\mathrm{km}$ comparison window even for clear sky conditions. For other flights, overlying clouds attenuated the lidar and obscured the viewing beneath, so it is not clear whether detectable levels of aerosols were present in the boundary layer in these cases. The 28 AAO flights where CALIPSO also retrieved extinction showed in situ median aerosol extinction up to about $20 \%$ higher than the 35 flights where CALIPSO observed no aerosol. Medians of the distributions of $550 \mathrm{~nm}$ extinction for the 35 "no retrieval" cases were typically in the $15-35 \mathrm{Mm}^{-1}$ range for flight levels in the boundary layer, and as discussed below this suggests that CALIPSO would not have retrieved aerosol extinctions in this range a substantial fraction of the time. We limited our retrievals to daytime profiles because the nighttime lidar profiles, while considerably less noisy, were too far removed in time for valid comparisons. For example, a 12-h time difference with winds at $10 \mathrm{~km}$ per hour puts the aerosols $120 \mathrm{~km}$ off track at AAO flight time, which is too far away to expect the PBL aerosols would be similar (Anderson et al., 2003). Additionally, diurnal changes in the height of the boundary layer would also affect the shape of the vertical profile.

Figure 14 shows statistical comparisons of AAO in situ extinction and CALIPSO lidar extinction data for the 28 profiles where collocated comparisons were possible. In order to understand the effects of boundary layer clouds on the comparisons, separate analyses of the cases with and without boundary layer clouds were performed. Of the 28 flights where CALIPSO detected aerosols in the proximal $35-\mathrm{km}$ satellite track, the vertical feature mask images showed 8 cases without and 20 cases with boundary layer clouds. The mean extinction profiles for the 8 cases without boundary layer clouds (Fig. 14a), the 20 cases with boundary layer clouds (Fig. 14b), and all 28 cases (Fig. 14c) are presented. The shaded envelopes represent standard deviations of the observations and the CALIPSO error bars are the propagated uncertainties of the lidar measurement (Winker et al., 2009; Young and Vaughan, 2009). The mean extinction for the cases without boundary layer clouds is smaller below $\sim 3 \mathrm{~km}$ for both instruments compared to the cases with boundary layer clouds. The agreement below $1 \mathrm{~km}$ is better between AAO and CALIPSO for the case without boundary layer clouds, except for the spike in CALIPSO extinction population at $0.9 \mathrm{~km}$. The extinction browse images show granules on two flights that could have caused this spike in the mean extinction profile. We suspect unidentified boundary layer clouds given the altitude, although this will require more study. It is interesting that the spike at $1.2 \mathrm{~km}$ in the case with boundary layer clouds is reduced significantly in the case without boundary layer clouds. This supports our hypothesis that cloud contamination could be occurring, particularly at that altitude. 

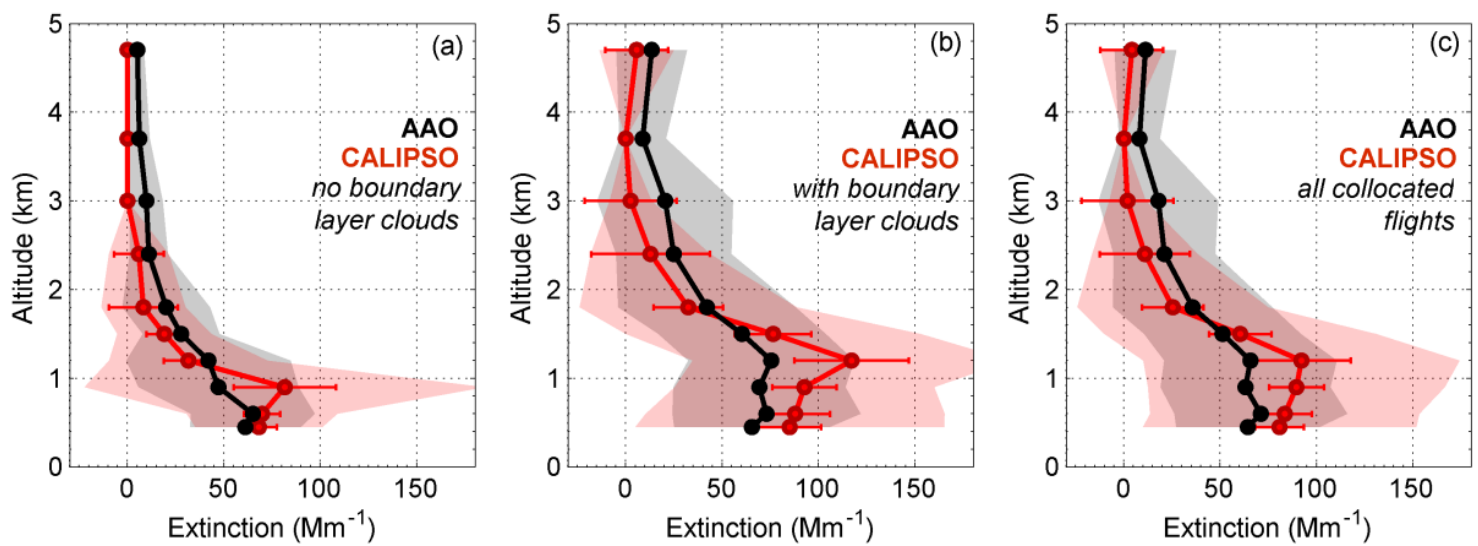

Fig. 14. Cumulative statistics of the mean extinction profiles of the 28 collocated in situ AAO and CALIPSO lidar comparisons. The shaded envelopes are standard deviations of the observations and the CALIPSO error bars are the propagated uncertainties of the lidar measurement. (a) No observed boundary layer clouds in proximal satellite track (8 cases). (b) Boundary layer clouds observed in proximal satellite track (20 cases). (c) All 28 collocated flights where CALIPSO retrieved extinction in the profile.
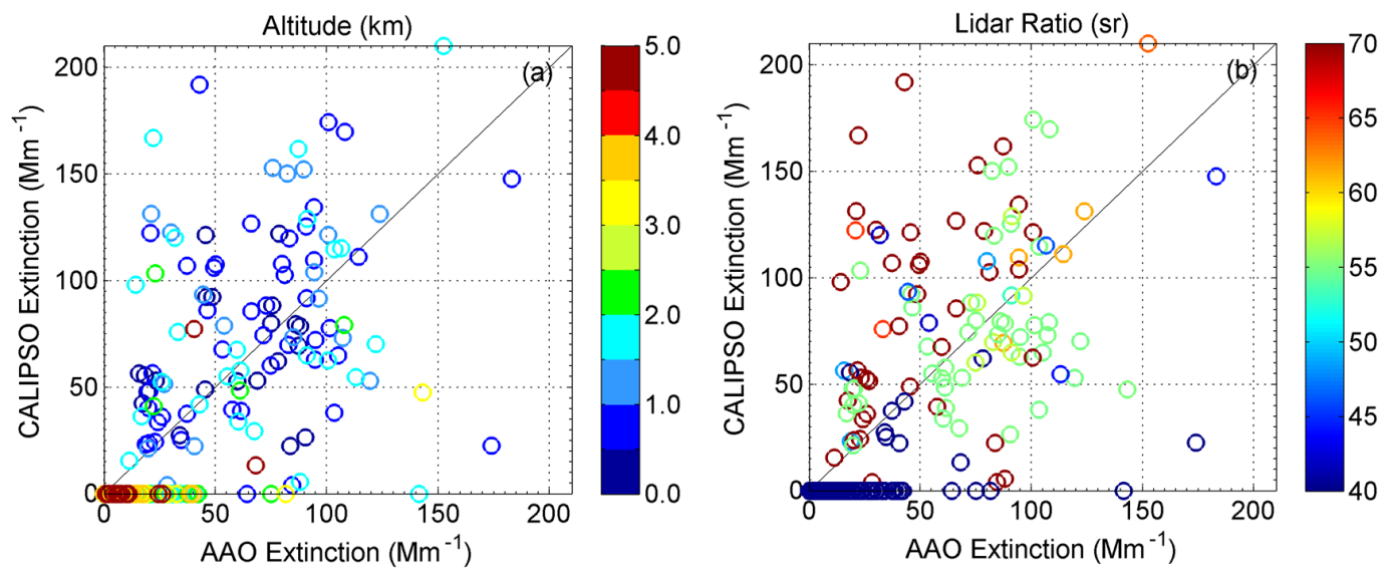

Fig. 15. Individual flight segment extinction comparisons, color coded by (a) altitude and (b) CALIOP lidar ratio.

These statistical compilation plots suggest that CALIPSO tends to overestimate the extinction in the boundary layer at this location while underestimating the extinction in the free troposphere. Imperfect cloud masking may explain some of the higher satellite extinction observations that influence the larger mean values between $\sim 0.4$ and $1.5 \mathrm{~km}$ altitude. Some individual lidar profiles show large "extinction" peaks that were observed to be much smaller by aircraft at altitudes where scattered clouds were present. The lower CALIPSO extinction values in the FT are likely related to CALIOP aerosol detection limits. In the flight segments where AAO detected relatively low levels of in situ extinction, CALIOP generally did not get a valid retrieval (defined as "clear air" cases). In these cases extinction values of $0.0 \mathrm{Mm}^{-1}$ were averaged into the compilations, so these free tropospheric lidar values are clearly lower limits. For example, the CALIPSO mean value at $3.7 \mathrm{~km}$ is $0.0 \mathrm{Mm}^{-1}$, meaning that CALIPSO did not get a valid retrieval at this altitude for any of the
28 collocated cases. This is not surprising given the low in situ extinction values and the noisy daytime retrievals. There is currently no known uncertainty to assign for CALIPSOdefined clear air cases. Limiting the averages to the aerosol layers detected by CALIPSO would mean that the averages only represent enhanced conditions and would be biased high.

Figure 15 shows the extinction comparison for each flight segment color coded by altitude (a) and lidar ratio (b). In Fig. 15a, the data points lying along the $\mathrm{x}$-axis (CALIPSO extinction $=0.0 \mathrm{Mm}^{-1}$ ) are mostly from the higher-altitude comparisons where in situ extinction was low and aerosol layers were undetected by CALIPSO. There are a few data points that show higher in situ extinction that were not detected by the CALIOP lidar. There is also a population of large $\left(>100 \mathrm{Mm}^{-1}\right)$ CALIPSO extinction values, typically at lower altitudes, that do not correspond with equally large AAO extinction values. These most likely represent the 
Table 4. Aerosol types and lidar ratios identified by CALIPSO during AAO overpasses.

\begin{tabular}{lcc}
\hline Aerosol Type & $\begin{array}{c}\text { Lidar Ratio } \\
(\mathrm{sr})\end{array}$ & $\begin{array}{c}\text { Percent of } \\
\text { Samples (\%) }\end{array}$ \\
\hline Dust & 40 & 15 \\
Polluted dust & 55 & 46 \\
Polluted continental & 70 & 24 \\
Smoke & 70 & 15 \\
\hline
\end{tabular}

comparisons where the cloud screening process should have eliminated these satellite data from consideration but did not. This population of large CALIPSO extinction values relative to AAO could, however, result from either misidentification of aerosol type or incorrect assignment of lidar ratio, or both. The lidar ratio (ratio of extinction to backscatter) is required by the CALIPSO algorithms to retrieve extinction from backscatter and varies by aerosol type. Figure $15 \mathrm{~b}$ shows the AAO vs. CALIPSO extinction with the lidar ratio identified for each comparison point. Many of these higher CALIPSO extinction values were derived using high lidar ratios of around 70 (dark red circles).

Aerosol types identified by CALIPSO are shown in Table 4 for the 28 collocated flights. Most aerosol samples in this regime $(46 \%)$ are classified as polluted dust with a lidar ratio of $55 \mathrm{sr}$. However, $39 \%$ of samples are classified as either polluted continental or smoke aerosol types, both having lidar ratios of $70 \mathrm{sr}$. If this lidar ratio is too large for aerosol in these cases the retrieved extinction will be overestimated and could contribute to the large CALIPSO extinction values since errors in retrieved extinction are roughly proportional to errors in the assumed lidar ratio. Indeed, Anderson et al. (2000) measured lidar ratio values at BND of $64 \pm 4 \mathrm{sr}$ which, if representative of aerosol measured during these 28 flights, could account for some of the discrepancy in extinction below $1.5 \mathrm{~km}$. Aerosols classified by CALIPSO as dust comprise $15 \%$ of the samples and the vast majority of higher altitude $(\geq 3.0 \mathrm{~km})$ samples were classified as this aerosol type. This supports the suggestion from the in situ AAO intensive parameters of larger mean particle sizes at higher altitudes.

Our long-term aircraft data permit the compilation of CALIPSO extinction detection efficiency as a function of in situ extinction level. The data from all 28 collocated aircraft profiles are shown in Fig. 16. The number of discrete comparison points represented in this figure is 244 ; that is the number of the 280 total flight segments that the AAO made a valid extinction (i.e., scattering plus absorption) measurement. The in situ AAO extinction is grouped into $10 \mathrm{Mm}^{-1}$ bins, and the number of cases in which CALIPSO detected extinction in each range bin is shown above each column.

Figure 16 can provide a clue as to how prevalent the potential problem of aerosol layers changing altitudes over

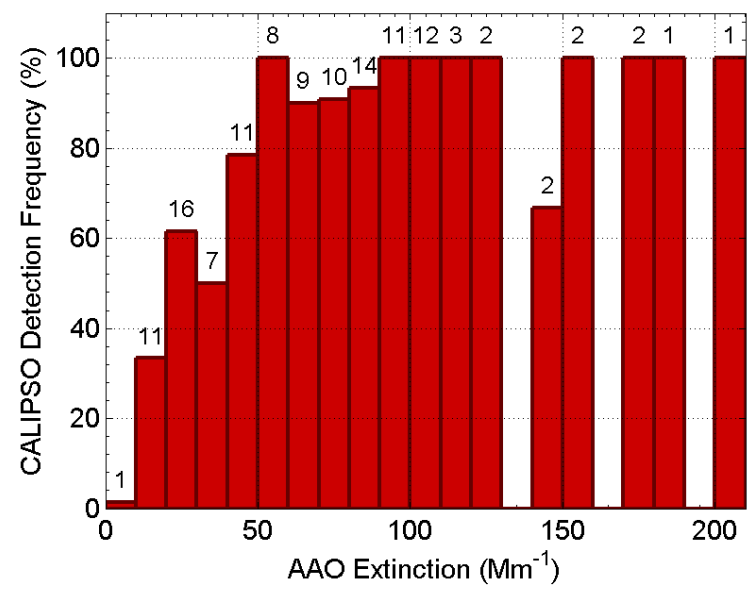

Fig. 16. CALIPSO extinction detection frequency as a function of AAO in situ extinction. Numbers above bars indicate the number of valid CALIPSO aerosol extinction retrievals falling within each AAO extinction range bin.

the $35-\mathrm{km}$ path might be. For in situ extinction values above $50 \mathrm{Mm}^{-1}$, CALIPSO retrieved a valid extinction value $\sim 95 \%$ of the time. The only bin where CALIPSO clearly missed the extinction was in the $140-150 \mathrm{Mm}^{-1}$ bin, where it retrieved only 2 of the 3 segments that fell into that bin. Closer inspection of this one missed case revealed that CALIPSO retrieved a clear air extinction value near what was measured by the aircraft in the adjacent vertical range bin. The CALIPSO measurement for this point was made 22 min after the AAO measurement. It is possible that the aerosol layer rose 30-60 m over this period of time and was classified into the adjacent bin. There are other possibilities also, but a detailed analysis of these individual comparisons is beyond the scope of this paper. In this one case, we can clearly say that vertical averaging of the CALIPSO data would have helped to detect a layer sampled by the aircraft. This does not appear to be a problem that was observed frequently. It is possible that CALIPSO also occasionally missed retrieving extinction in the 60-70, 70-80, and 80$90 \mathrm{Mm}^{-1}$ bins, but this could also be due to cloud contamination issues as much as aerosol layers changing height.

For in situ extinction levels larger than $50 \mathrm{Mm}^{-1}$, CALIPSO makes a retrieval $\sim 95 \%$ of the time (77 out of 81 cases). For the $40-50 \mathrm{Mm}^{-1}$ extinction bin, CALIPSO's retrieval frequency drops to $<80 \%$. Below about $20 \mathrm{Mm}^{-1}$, CALIPSO detected aerosol extinction only in about $11 \%(12$ out of 109) of the cases, and below $10 \mathrm{Mm}^{-1}$, CALIPSO rarely ( 1 case in 76$)$ retrieved any extinction. For all 244 cases, a $50 \%$ probability of detection falls at an in situ extinction level of $20-25 \mathrm{Mm}^{-1}$. 


\section{Conclusions}

Over 400 vertical profiles of in situ aerosol properties were obtained using a light aircraft over eastern and central Illinois between June 2006 and September 2009. A majority of the aircraft profiles were flown near a NOAA/ESRL surface aerosol monitoring station where identical aerosol measurements were being conducted. The vertical profile measurements were conducted to build a robust database of aerosol properties aloft for the purposes of assessing aerosol variability in the vertical and determining how representative surface aerosol measurements are of those in the lower column. In addition, individual profiles from this program were compared with CALIPSO lidar extinction measurements in order to provide "air truth" measurements for satellite retrieval validation exercises.

Flyby comparison measurements showed good agreement between those from the low altitude aircraft flyby segment and those conducted with similar or identical instruments at the surface. Excellent agreement was obtained for light scattering by submicrometer aerosols, and agreement was acceptable even for the "total" size fraction (particles up to the $5 \mu \mathrm{m}$ diameter efficiently sampled by the aircraft inlet), indicating no major sampling problems for the aircraft inlet or instruments.

Extensive aerosol properties show that the amount of aerosol decreases strongly with increasing altitude to the top of the mixed layer, and more slowly after that. Much less variability was observed in the intensive properties. Several aerosol parameters suggest a lesser contribution to aerosol optical properties from smaller particles at the higher altitudes. This could be due to increased small particle sources at the surface or more efficient removal mechanisms for the smaller particles at higher altitudes owing to their size and/or composition. The median aerosol absorption Ångström exponent increased from just over 1.0 in the lower portion of the mixed layer to $\sim 1.4$ at the highest flight altitude. A larger $\mathrm{a}_{\mathrm{a}}$ suggests that dust or organic material may be on or in the particles to a larger extent. A larger dust or organic component in the aerosol may be responsible for the larger particles surviving precipitation and scavenging processes due to a lower hygroscopicity of those substances. Aerosol scattering hygroscopic growth measurements made during a subset of profiles show less-hygroscopic aerosols at higher profile altitudes. Scattering hygroscopic growth factor medians were observed to be $>2.0$ in the PBL and $<2.0$ in the free troposphere.

Aerosols over Illinois show clear statistical differences among seasons. Seasonal differences include more extinction in the column in the summer and less in the winter, with spring and fall profile medians falling in between the extremes. The springtime profiles, however, show the largest extinction values of any season above $3 \mathrm{~km}$ a.s.l. In general the lowest $\omega_{0}$ values in the column were observed in the fall, and this is consistent with the fall minimum in $\omega_{0}$ observed in the surface measurements. AAO-derived RFE showed very little vertical or seasonal variability. Barring large differences in aerosol hygroscopicity and RH (which are observed in some individual profiles but not in the cumulative statistics), these data suggest that surface measurements of aerosol optical properties could be used, on average, to estimate column RFE. However, an instantaneous retrieval of RFE using surface properties could be in error.

The individual AAO/CALIPSO extinction comparison cases that comprised this study hold a wealth of information for verifying the satellite retrievals. Our purpose was to show how well, in a statistical sense, the satellite data agreed with our in situ extinction data. AAO underflights of the CALIPSO satellite show generally good agreement between aircraft-measured and satellite-retrieved extinction for our limited subset of collocated profiles where clouds were not prevalent. We have observed that CALIPSO often overestimates extinction in the PBL at this location, possibly due to interferences from clouds that are not screened properly from the retrieval, but determining the specific causes for these discrepancies in individual profiles is beyond the scope of this work. Our long-term data suggest that if light extinction at $532 \mathrm{~nm}$ in atmospheric aerosol layers exceeds $50 \mathrm{Mm}^{-1}$, CALIPSO will retrieve an extinction value $\sim 95 \%$ of the time. The in situ extinction threshold at $532 \mathrm{~nm}$ for a $50 \%$ probability of detection by CALIPSO is $20-25 \mathrm{Mm}^{-1}$. We expect to investigate the individual profile comparison cases in more detail in a future paper.

\section{Appendix A}

\section{CALIPSO data quality screening}

CALIPSO aerosol extinction data are quality screened using metrics reported in the Level 2 aerosol profile data product which indicate the algorithm's ability to determine the correct atmospheric feature type (aerosol or cloud) and the final state of the extinction retrieval algorithm. These quality screening filters are based on those used to generate the CALIPSO Level 3 aerosol profile product from Level 2 aerosol profile data; rationale and further details are described in Winker et al. (2012).

Each layer detected by the CALIPSO feature classification algorithms is given a Cloud-Aerosol-Discrimination (CAD) Score, a metric indicating the confidence in determining if the layer is an aerosol or a cloud. If CAD $=-100$, it reflects that layer is most likely aerosol, $\mathrm{CAD}=100$ reflects that the layer is most likely cloud, and CAD $=0$ reflects inability to distinguish between aerosol or cloud (Liu et al., 2009). We required the CAD score to be less than -20 to reduce the possibility of including clouds misclassified as aerosol.

In order to retrieve aerosol extinction from total attenuated backscatter, the quantity measured by the CALIPSO lidar, an initial lidar ratio (ratio of aerosol extinction to backscatter) 
is assumed based on the aerosol type determined by the automated aerosol subtyping algorithm (Young and Vaughan, 2009; Omar et al., 2009). At times during the extinction retrieval the initial lidar ratio may be adjusted to converge to a solution. An Extinction QC Flag is assigned for the extinction retrieval of each aerosol layer which summarizes the final state of the retrieval solution. We required that Extinction QC flag be $0,1,16$, or 18 , indicating that the either the initial lidar ratio was unchanged ( 0$)$, the initial lidar ratio was measured based on the layer transmittance (1), the layer was opaque with an unchanged lidar ratio (16), or that the layer was opaque and the lidar ratio was reduced to avoid a divergent solution (18), respectively. Extinction uncertainty is reported along with each extinction value in the CALIPSO Level 2 aerosol profile product. A flag value of $99000 \mathrm{Mm}^{-1}$ is used to indicate that the extinction uncertainty solution is diverging to infinity, in which case the extinction retrieval should be discarded. We require extinction uncertainty to be less than $99000 \mathrm{Mm}^{-1}$ to remove these cases. Furthermore, aerosol layers detected beneath clouds are not used because cloud attenuation may significantly reduce the signalto-noise ratio and impact the retrieved aerosol extinction solutions at lower altitudes.

Acknowledgements. The authors wish to thank our pilot, Stan Unander, of the University of Illinois Institute for Aviation, for flying our profiles and being the on-site science technician, and Chuck Greenwood of The Greenwood Group for providing a safe and effective aircraft platform. We also thank Jim Wendell and Robert Albee of NOAA/ESRL for systems engineering and fabrication, and Derek Hageman of NOAA/ESRL for data acquisition and visualization software. We gratefully acknowledge funding for this project from the NOAA Climate Program Office.

Edited by: A. Petzold

\section{References}

Anderson, T. L. and Ogren, J. A.: Determining aerosol radiative properties using the TSI 3563 integrating nephelometer, Aerosol Sci. Technol., 29, 57-69, 1998.

Anderson, T. L., Covert, D. S., Wheeler, J. D., Harris, J. M., Perry, K. D., Trost, B. E., Jaffe, D. J., and Ogren, J. A.: Aerosol backscatter fraction and single-scattering albedo: Measured values and uncertainties at a coastal station in the Pacific Northwest, J. Geophys. Res., 104, 26793-26807, doi:10.1029/1999JD900172, 1999.

Anderson, T. L., Masonis, S. J., Covert, D. S., Charlson, R. J., and Rood, M. J.: In situ measurement of the aerosol extinction-tobackscatter ratio at a polluted continental site, J. Geophys. Res., 105, 26907-26915, doi:10.1029/2000JD900400, 2000.

Anderson, T. L., Charlson, R. J., Winker, D. M., Ogren, J. A., and Holmén, K.: Mesoscale Variations of Tropospheric Aerosols, J. Atmos. Sci., 60, 119-136, 2003.

Andreae, M. O. and Gelencsér, A.: Black carbon or brown carbon? The nature of light-absorbing carbonaceous aerosols, At- mos. Chem. Phys., 6, 3131-3148, doi:10.5194/acp-6-3131-2006, 2006.

Andrews, E., Sheridan, P. J., Ogren, J. A., and Ferrare, R.: In situ aerosol profiles over the Southern Great Plains cloud and radiation testbed site: 1. Aerosol optical properties, J. Geophys. Res., 109, D06208, doi:10.1029/2003JD004025, 2004.

Andrews, E., Sheridan, P. J., Fiebig, M., McComiskey, A., Ogren, J. A., Arnott, P., Covert, D., Elleman, R., Gasparini, R., Collins, D., Jonsson, H., Schmid, B., and Wang, J.: Comparison of methods for deriving aerosol asymmetry parameter, J. Geophys. Res., 111, D05S04, doi:10.1029/2004JD005734, 2006.

Andrews, E., Sheridan, P. J., and Ogren, J. A.: Seasonal differences in the vertical profiles of aerosol optical properties over rural Oklahoma, Atmos. Chem. Phys., 11, 10661-10676, doi:10.5194/acp-11-10661-2011, 2011.

Augustine, J. A., Hodges, G. B., Dutton, E. G., Michalsky, J. J., and Cornwall, C. R.: An aerosol optical depth climatology for NOAA's national surface radiation budget network (SURFRAD), J. Geophys. Res., 113, D11204, doi:10.1029/2007JD009504, 2008.

Bergstrom, R. W.: Extinction and absorption coefficients of the atmospheric aerosol as a function of particle size, Contr. Atmos. Phys., 46, 223-234, 1973.

Bergstrom, R. W., Pilewskie, P., Pommier, J., Rabbette, M., Russell, P. B., Schmid, B., Redemann, J., Higurashi, A., Nakajima, T., and Quinn, P. K.: Spectral absorption of solar radiation by aerosols during ACE-Asia, J. Geophys. Res., 109, D19S15, doi:10.1029/2003JD004467, 2004.

Bergstrom, R. W., Pilewskie, P., Russell, P. B., Redemann, J., Bond, T. C., Quinn, P. K., and Sierau, B.: Spectral absorption properties of atmospheric aerosols, Atmos. Chem. Phys., 7, 5937-5943, doi:10.5194/acp-7-5937-2007, 2007.

Berkowitz, C., Berg, L. K., Yu, X.-Y., Alexander, M. L, Laskin, A., Xie, Y., Jobson, B. T., Andrews, E., and Ogren, J.: The influence of fog and airmass history on aerosol optical, physical and chemical properties at Pt. Reyes National Seashore, Atmos. Environ., 45, 2559-2568, 2011.

Bodhaine, B. A.: Aerosol measurements at four background sites, J. Geophys. Res., 88, 10753-10768, doi:10.1029/JC088iC15p10753, 1983.

Bodhaine, B. A.: Aerosol absorption measurements at Barrow, Mauna Loa and the South Pole, J. Geophys. Res., 100, 89678975, doi:10.1029/95JD00513, 1995.

Bodhaine, B. A. and Dutton, E. G.: A long term decrease in Arctic haze at Barrow, Alaska, Geophys. Res. Lett., 20, 947-950, doi:10.1029/93GL01146, 1993.

Bohren, C. F. and Huffman, D. R.: Absorption and Scattering of Light by Small Particles, John Wiley and Sons, New York, 530 pp., 1983.

Bond, T. C. and Bergstrom, R. W.: Light absorption by carbonaceous particles: An investigative review, Aerosol Sci. Technol., 40, 27-67, doi:10.1080/02786820500421521, 2006.

Bond, T. C., Anderson, T. L., and Campbell, D.: Calibration and intercomparison of filter-based measurements of visible light absorption by aerosols, Aerosol Sci. Technol., 30, 582-600, doi:10.1080/027868299304435, 1999.

Charlson, R. J., Langner, J., Rodhe, H., Leovy, C. B., and Warren, S. G.: Perturbation of the northern hemisphere radiative balance by backscattering from anthropogenic sulfate aerosols, Tellus, 
43AB, 152-163, 1991.

Clarke, A. D., Shinozuka, Y., Kapustin, V. N., Howell, S., Huebert, B., Doherty, S., Anderson, T., Covert, D., Anderson, J., Hua, X., Moore II, K. G., McNaughton, C., Carmichael, G., and Weber, R.: Size distributions and mixtures of dust and black carbon aerosol in Asian outflow: Physiochemistry and optical properties, J. Geophys. Res., 109, D15S09, doi:10.1029/2003JD004378, 2004.

Collaud Coen, M., Weingartner, E., Schaub, D., Hueglin, C., Corrigan, C., Henning, S., Schwikowski, M., and Baltensperger, U.: Saharan dust events at the Jungfraujoch: detection by wavelength dependence of the single scattering albedo and first climatology analysis, Atmos. Chem. Phys., 4, 2465-2480, doi:10.5194/acp4-2465-2004, 2004.

Delene, D. J. and Ogren, J. A.: Variability of aerosol optical properties at four North American surface monitoring sites, J. Atmos. Sci., 59, 1135-1150, 2002.

Dubovik, O. and King, M. D.: A flexible inversion algorithm for retrieval of aerosol optical properties from sun and sky radiance measurements, J. Geophys. Res., 105, 20673-20696, doi:10.1029/2000JD900282, 2000.

Eck, T. F., Holben, B. N., Reid, J. S., O’Neill, N. T., Schafer, J. S., Dubovik, O., Smirnov, A., Yamasoe, M. A., and Artaxo, P.: High aerosol optical depth biomass burning events: A comparison of optical properties for different source regions, Geophys. Res. Lett., 30, 2035, doi:10.1029/2003GL017861, 2003.

Eck, T. F., Holben, B. N., Dubovik, O., Smirnov, A., Goloub, P., Chen, H. B., Chatenet, B., Gomes, L., Zhang, X.-Y., Tsay, S.C., Ji, Q., Giles, D. M., and Slutsker, I.: Columnar aerosol optical properties at AERONET sites in central eastern Asia and aerosol transport to the tropical mid-Pacific, J. Geophys. Res., 110, D06202, doi:10.1029/2004JD005274, 2005.

Ensor, D. S., Charlson, R. J., Ahlquist, N. C., Whitby, K. T., Husar, R. B., and Liu, B. Y. H.: Multiwavelength nephelometer measurements in Los Angeles smog aerosol - I. Comparison of calculated and measured light scattering, J. Colloid Interface Sci., 39, 242-251, 1972.

Esteve, A. R., Ogren, J. A., Sheridan, P. J., Andrews, E., Holben, B. N., and Utrillas, M. P.: Sources of discrepancy between aerosol optical depth obtained from AERONET and in-situ aircraft profiles, Atmos. Chem. Phys., 12, 2987-3003, doi:10.5194/acp-122987-2012, 2012.

Ferrare, R. A., Feingold, G., Ghan, S., Ogren, J., Schmid, B., Schwartz, S. E., and Sheridan, P.: Preface to the special section: Atmospheric Radiation Measurement Program May 2003 Intensive Operations Period examining aerosol properties and radiative influences, J. Geophys. Res., 111, D05S01, doi:10.1029/2005JD006908, 2006.

Fialho, P., Hansen, A. D. A., and Honrath, R. E.: Absorption coefficients by aerosols in remote areas: A new approach to decouple dust and black carbon absorption coefficients using seven wavelength Aethalometer data, J. Aerosol Sci., 36, 267-282, 2005.

Gassó, S., Hegg, D. A., Covert, D. S., Collins, D., Noone, K. J., Öström, E., Schmid, B., Russell, P. B., Livingston, J. M., Durkee, P. A., and Jonsson, H.: Influence of humidity on the aerosol scattering coefficient and its effect on the upwelling radiance during ACE-2, Tellus B, 52, 546-567, doi:10.1034/j.16000889.2000.00055.x, 2000.
Hains, J. C., Taubman, B. F., Thompson, A. M., Stehr, J. W., Marufu, L. T., Doddridge, B. G., and Dickerson, R. R.: Origins of chemical pollution derived from Mid-Atlantic aircraft profiles using a clustering technique, Atmos. Environ., 42, 1727-1741, 2008.

Haywood, J. M. and Shine, K. P.: The effect of anthropogenic sulfate and soot aerosol on the clear sky planetary radiation budget, Geophys. Res. Lett., 22, 603-606, doi:10.1029/95GL00075, 1995.

Holben, B. N., Eck, T. F., Slutsker, I., Tanré, D., Buis, J. P., Setzer, A., Vermote, E., Reagan, J. A., Kaufman, Y. J., Nakajima, T., Lavenu, F., Jankowiak, I., and Smirnov, A.: AERONET - A federated instrument network and data archive for aerosol characterization, Remote Sens. Environ., 66, 1-16, 1998.

Holben, B. N., Tanre, D., Smirnov, A., Eck, T. F., Slutsker, I., Abuhassan, N., Newcomb, W., and Schafer, J. S.: An emerging ground-based aerosol climatology: Aerosol optical depth from AERONET, J. Geophys. Res., 106, 12067-12097, doi:10.1029/2001JD900014, 2001.

Huebert, B. J., Howell, S. G., Covert, D., Bertram, T., Clarke, A., Anderson, J. R., Lafleur, B. G., Seebaugh, W. R., Wilson, J. C., Gesler, D., Blomquist, B., and Fox, J.: PELTI: Measuring the passing efficiency of an airborne low turbulence aerosol inlet, Aerosol Sci. Technol., 38, 803-826, doi:10.1080/027868290500823, 2004.

Intergovernmental Panel on Climate Change (IPCC): Climate Change 2007: The Scientific Basis, Contribution of Working Group I to the Fourth Assessment Report of the Intergovernmental Panel on Climate Change, edited by: Solomon, S., Qin, D., Manning, M., Chen, Z., Marquis, M., Averyt, K. B., Tignor, M., and Miller, H. L., Cambridge Univ. Press, New York, NY, 2007.

Kasten, F.: Visibility in the phase of pre-condensation, Tellus, 21, 631-635, 1969.

Kirchstetter, T. W., Novakov, T., and Hobbs, P.: Evidence that the spectral dependence of light absorption by aerosols is affected by organic carbon, J. Geophys. Res., 109, D21208, doi:10.1029/2004JD004999, 2004.

Koloutsou-Vakakis, S., Carrico, C. M., Kus, P., Rood, M. J., Li, Z., Shrestha, R., Ogren, J. A., Chow, J. C., and Watson, J. G.: Aerosol properties at a midlatitude Northern Hemisphere continental site, J. Geophys. Res., 106, 3019-3032, doi:10.1029/2000JD900126, 2001.

Liu, Z., Vaughan, M. A., Winker, D. M., Kittaka, C., Kuehn, R. E., Getzewich, B. J., Trepte, C. R., and Hostetler, C. A.: The CALIPSO Lidar Cloud and Aerosol Discrimination: Version 2 Algorithm and Initial Assessment of Performance, J. Atmos. Ocean. Tech., 26, 1198-1213, doi:10.1175/2009JTECHA1229.1, 2009.

Marcq, S., Laj, P., Roger, J. C., Villani, P., Sellegri, K., Bonasoni, P., Marinoni, A., Cristofanelli, P., Verza, G. P., and Bergin, M.: Aerosol optical properties and radiative forcing in the high Himalaya based on measurements at the Nepal Climate Observatory-Pyramid site (5079 m a.s.1.), Atmos. Chem. Phys., 10, 5859-5872, doi:10.5194/acp-10-5859-2010, 2010.

Massoli, P., Murphy, D. M., Lack, D. A., Baynard, T., Brock, C. A., and Lovejoy, E. R.: Uncertainty in light scattering measurements by TSI nephelometer: Results from laboratory studies and implications for ambient measurements, Aerosol Sci. Technol., 43, 1064-1074, doi:10.1080/02786820903156542, 2009. 
McFiggans, G., Artaxo, P., Baltensperger, U., Coe, H., Facchini, M. C., Feingold, G., Fuzzi, S., Gysel, M., Laaksonen, A., Lohmann, U., Mentel, T. F., Murphy, D. M., O’Dowd, C. D., Snider, J. R., and Weingartner, E.: The effect of physical and chemical aerosol properties on warm cloud droplet activation, Atmos. Chem. Phys., 6, 2593-2649, doi:10.5194/acp-6-2593-2006, 2006.

McNaughton, C. S., Clarke, A. D., Howell, S. G., Pinkerton, M., Anderson, B., Thornhill, L., Hudgins, C., Winstead, E., Dibb, J. E., Scheuer, E., and Maring, H.: Results from the DC-8 Inlet Characterization Experiment (DICE): Airborne versus surface sampling of mineral dust and sea salt aerosols, Aerosol Sci. Technol., 41, 136-159, doi:10.1080/02786820601118406, 2007.

Moosmüller, H., Chakrabarty, R. K., and Arnott, W. P.: Aerosol light absorption and its measurement: A review, J. Quant. Spectrosc. Ra., 110, 844-878, 2009.

Müller, D., Wandinger, U., Althausen, D., and Fiebig, M.: Comprehensive particle characterization from three-wavelength Ramanlidar observations: Case study, Appl. Optics, 40, 4863-4869, 2001.

Müller, T., Nowak, A., Wiedensohler, A., Sheridan, P., Laborde, M., Covert, D. S., Marinoni, A., Imre, K., Henzing, B., Roger, J.-C., dos Santos, S. M., Wilhelm, R., Wang, Y.-Q., and de Leeuw, G.: Angular illumination and truncation of three different integrating nephelometers: Implications for empirical, size-based corrections, Aerosol Sci. Technol., 43, 581-586, 2009.

Myhre, G.: Consistency between satellite-derived and modeled estimates of the direct aerosol effect, Science, 325, 187-190, doi:10.1126/science.1174461, 2009.

Ogren, J. A.: In situ observations of aerosol properties, in: Aerosol Forcing of Climate, edited by: Charlson, R. J. and Heintzenberg, J., 215-226, J. Wiley, Hoboken, NJ, 1995.

Ogren, J. A.: Comment on "Calibration and Intercomparison of Filter-Based Measurements of Visible Light Absorption by Aerosols", Aerosol Sci. Technol., 44, 589-591, doi:10.1080/02786826.2010.482111, 2010.

Omar, A., Winker, D., Kittaka, C., Vaughan, M., Liu, Z., Hu, Y., Trepte, C., Rogers, R., Ferrare, R., Kuehn, R., and Hostetler, C.: The CALIPSO Automated Aerosol Classification and Lidar Ratio Selection Algorithm, J. Atmos. Ocean. Tech., 26, 1994-2014, doi:10.1175/2009JTECHA1231.1, 2009.

Quinn, P. K., Bates, T. S., Baynard, T., Clarke, A. D., Onasch, T. B., Wang, W., Rood, M. J., Andrews, E., Allan, J., Carrico, C. M., Coffman, D., and Worsnop, D.: Impact of particulate organic matter on the relative humidity dependence of light scattering: A simplified parameterization, Geophys. Res. Lett., 32, L22809, doi:10.1029/2005GL024322, 2005.

Rahn, K. A., Borys, R. D., and Shaw, G. E.: The Asian source of Arctic haze bands, Nature, 268, 713-715, doi:10.1038/268713a0, 1977.

Ramanathan, V., Crutzen, P. J., Lelieveld, J., Mitra, A. P., Althausen, D., Anderson, J., Andreae, M. O., Cantrell, W., Cass, G. R., Chung, C. E., Clarke, A. D., Coakley, J. A., Collins, W. D., Conant, W. C., Dulac, F., Heintzenberg, J., Heymsfield, A. J., Holben, B., Howell, S., Hudson, J., Jayaraman, A., Kiehl, J. T., Krishnamurti, T. N., Lubin, D, McFarquhar, G., Novakov, T., Ogren, J. A., Podgorny, I. A., Prather, K., Priestley, K., Prospero, J. M., Quinn, P. K., Rajeev, K., Rasch, P., Rupert, S., Sadourny, R., Satheesh, S. K., Shaw, G. E., Sheridan, P., and Valero, F. P. J.: The Indian Ocean Experiment: An integrated assessment of the climate forcing and effects of the great Indo-Asian haze, J. Geophys. Res., 106, 28371-28399, doi:10.1029/2001JD900133, 2001.

Rogers, R. R., Hair, J. W., Hostetler, C. A., Ferrare, R. A., Obland, M. D., Cook, A. L., Harper, D. B., Burton, S. P., Shinozuka, Y., McNaughton, C. S., Clarke, A. D., Redemann, J., Russell, P. B., Livingston, J. M., and Kleinman, L. I.: NASA LaRC airborne high spectral resolution lidar aerosol measurements during MILAGRO: observations and validation, Atmos. Chem. Phys., 9, 4811-4826, doi:10.5194/acp-9-4811-2009, 2009.

Rozwadowska, A.: Influence of aerosol vertical profile variability on retrievals of aerosol optical thickness from NOAA AVHRR measurements in the Baltic region, Oceanologia, 49, 165-184, 2007.

Schnaiter, M., Gimmler, M., Llamas, I., Linke, C., Jäger, C., and Mutschke, H.: Strong spectral dependence of light absorption by organic carbon particles formed by propane combustion, Atmos. Chem. Phys., 6, 2981-2990, doi:10.5194/acp-6-2981-2006, 2006.

Sheridan, P. J. and Ogren, J. A.: Observations of the vertical and regional variability of aerosol optical properties over central and eastern North America, J. Geophys. Res., 104, 16793-16805, doi:10.1029/1999JD900241, 1999.

Sheridan, P. J., Delene, D. J., and Ogren, J. A.: Four years of continuous surface aerosol measurements from the Department of Energy's Atmospheric Radiation Measurement Program Southern Great Plains Cloud and Radiation Testbed site, J. Geophys. Res., 106, 20735-20747, doi:10.1029/2001JD000785, 2001.

Sheridan, P. J., Jefferson, A., and Ogren, J. A.: Spatial variability of submicrometer aerosol radiative properties over the Indian Ocean during INDOEX, J. Geophys. Res., 107, 8011, doi:10.1029/2000JD000166, 2002.

Shinozuka, Y., Clarke, A. D., Howell, S. G., Kapustin, V. N., McNaughton, C. S., Zhou, J., and Anderson, B. E.: Aircraft profiles of aerosol microphysics and optical properties over North America: Aerosol optical depth and its association with $\mathrm{PM}_{2.5}$ and water uptake, J. Geophys. Res., 112, D12S20, doi:10.1029/2006JD007918, 2007.

Taubman, B. F., Hains, J. C., Thompson, A. M., Marufu, L. T., Doddridge, B. G., Stehr, J. W., Piety, C. A., and Dickerson, R. R.: Aircraft vertical profiles of trace gas and aerosol pollution over the mid-Atlantic United States: Statistics and meteorological cluster analysis, J. Geophys. Res., 111, D10S07, doi:10.1029/2005JD006196, 2006.

Turner, D. D., Ferrare, R. A., and Brasseur, L. A.: Average aerosol extinction and water vapor profiles over the southern Great Plains, Geophys. Res. Lett., 28, 4441-4444, doi:10.1029/2001GL013691, 2001.

VanCuren, R. A.: Asian aerosols in North America: Extracting the chemical composition and mass concentration of the Asian continental aerosol plume from long-term aerosol records in the western United States, J. Geophys. Res., 108, 4623, doi:10.1029/2003JD003459, 2003.

Vernier, J.-P., Thomason, L. W., Pommereau, J.-P., Bourassa, A., Pelon, J., Garnier, A., Hauchecorne, A., Blanot, L., Trepte, C., Degenstein, D., and Vargas, F.: Major influence of tropical volcanic eruptions on the stratospheric aerosol layer during the last decade, Geophys. Res. Lett., 38, L12807, doi:10.1029/2011GL047563, 2011. 
Verver, G., Raes, F., Vogelezang, D., and Johnson, D.: The second Aerosol Characterization Experiment (ACE-2): Meteorological and chemical context, Tellus 52B, 126-140, doi:10.1034/j.16000889.2000.00090.x, 2000.

Veselovskii, I., Kolgotin, A., Müller, D., and Whiteman, D. N.: Information content of multiwavelength lidar data with respect to microphysical particle properties derived from eigenvalue analysis, Appl. Optics, 44, 5292-5303, 2005.

Virkkula, A., Backman, J., Aalto, P. P., Hulkkonen, M., Riuttanen, L., Nieminen, T., dal Maso, M., Sogacheva, L., de Leeuw, G., and Kulmala, M.: Seasonal cycle, size dependencies, and source analyses of aerosol optical properties at the SMEAR II measurement station in Hyytiälä, Finland, Atmos. Chem. Phys., 11, 4445-4468, doi:10.5194/acp-11-4445-2011, 2011.

Weingartner, E., Nyeki, S., and Baltensperger, U.: Seasonal and diurnal variation of aerosol size distributions $(10<\mathrm{D}<750 \mathrm{~nm})$ at a high-alpine site (Jungfraujoch $3580 \mathrm{~m}$ asl), J. Geophys. Res., 104, 26809-26820, doi:10.1029/1999JD900170, 1999.

Winker, D. M., Vaughan, M. A., Omar, A. H., Hu, Y., Powell, K. A., Liu, Z., Hunt, W. H., and Young, S. A.: Overview of the CALIPSO Mission and CALIOP Data Processing Algorithms, J. Atmos. Oceanic Tech., 26, 2310-2323, doi:10.1175/2009JTECHA1281.1, 2009.

Winker, D. M., Tackett, J. L., Getzewich, B. J., Liu, Z., Vaughan, M. A., and Rogers, R. R.: The global 3-D distribution of tropospheric aerosols as characterized by CALIOP, Atmos. Chem. Phys. Discuss., 12, 24847-24893, doi:10.5194/acpd-12-248472012, 2012.
Wiscombe, W. J. and Grams, G. W.: The backscattered fraction in two-stream approximations, J. Atmos. Sci., 33, 2440-2451, 1976.

Young, S. A. and Vaughan, M. A.: The retrieval of profiles of particulate extinction from Cloud Aerosol Lidar Infrared Pathfinder Satellite Observations (CALIPSO) data: Algorithm description, J. Atmos. Ocean. Tech., 26, 1105-1119, doi:10.1175/2008JTECHA1221.1, 2009.

Yu, H., Kaufman, Y. J., Chin, M., Feingold, G., Remer, L. A., Anderson, T. L., Balkanski, Y., Bellouin, N., Boucher, O., Christopher, S., DeCola, P., Kahn, R., Koch, D., Loeb, N., Reddy, M. S., Schulz, M., Takemura, T., and Zhou, M.: A review of measurement-based assessments of the aerosol direct radiative effect and forcing, Atmos. Chem. Phys., 6, 613-666, doi:10.5194/acp-6-613-2006, 2006.

Yu, H., Chin, M., Winker, D. M., Omar, A. H., Liu, Z., Kittaka, C., and Diehl, T.: Global view of aerosol vertical distributions from CALIPSO lidar measurements and GOCART simulations: Regional and seasonal variations, J. Geophys. Res., 115, D00H30, doi:10.1029/2009JD013364, 2010. 